 \\ US Army Corps \\ of Engineers ${ }_{\circledast}$
}

Engineer Research and

Development Center

\section{Army R-22 Refrigerant Phase-Out Strategy}

James P. Miller, Anthony R. Latino, Chandana Konidala,

March 2021

Raymond Patenaude, and Gonzalo Perez

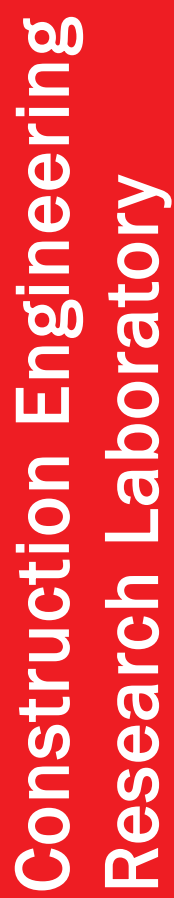

Overall Costs to Replace R-22 Equipment

- Replacement Cost for $30 \% \quad \square$ Replacement cost for $100 \%$

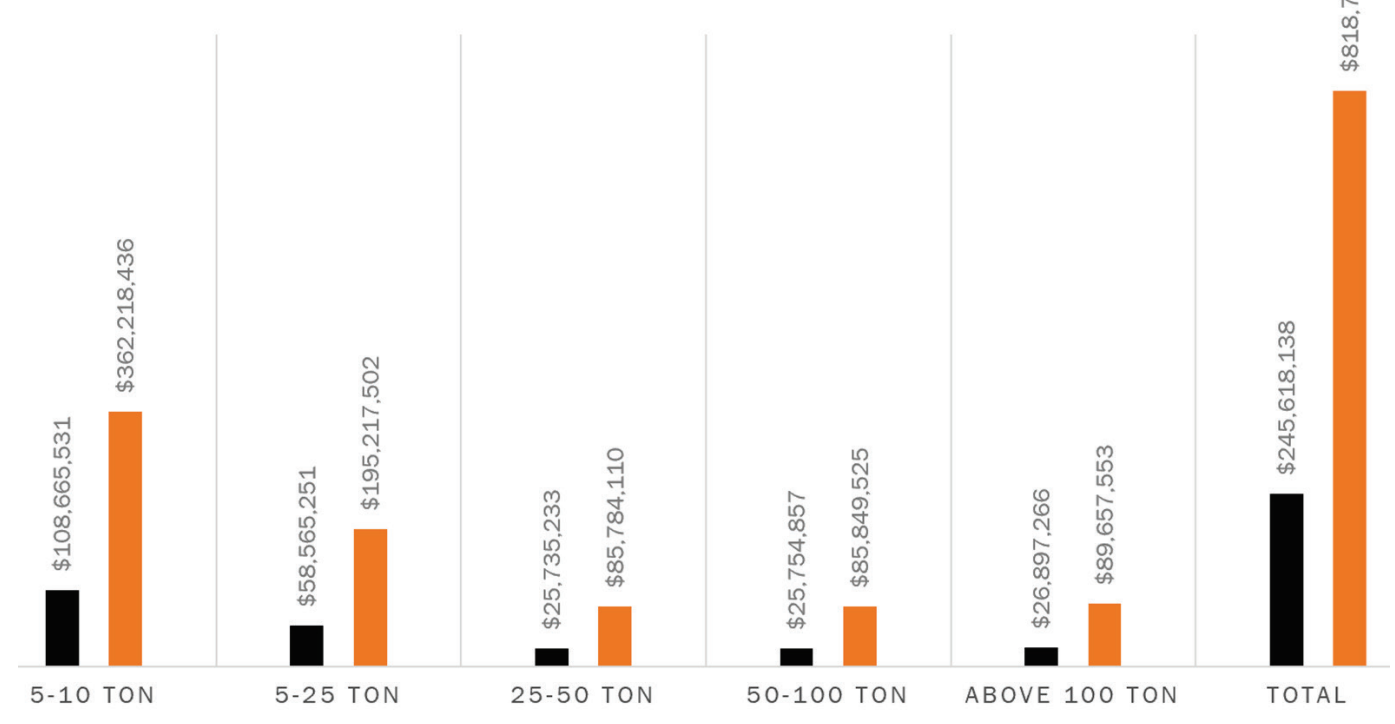


The U.S. Army Engineer Research and Development Center (ERDC) solves the nation's toughest engineering and environmental challenges. ERDC develops innovative solutions in civil and military engineering, geospatial sciences, water resources, and environmental sciences for the Army, the Department of Defense, civilian agencies, and our nation's public good. Find out more at www.erdc.usace.army.mil.

To search for other technical reports published by ERDC, visit the ERDC online library at https://erdclibrary.on.worldcat.org/discovery. 


\title{
Army R-22 Refrigerant Phase-Out Strategy
}

\author{
James P. Miller
}

U.S. Army Engineer Research and Development Center (ERDC)

Construction Engineering Research Laboratory (CERL)

2902 Newmark Dr.

Champaign, IL 61824

Anthony R. Latino, Chandana Konidala, and Gonzalo Perez

SC-B Consulting, Inc.

44 East Main Street, Suite 513

Champaign, Illinois 61820

Raymond Patenaude

Holmes Engineering Group

44 East Main Street, Suite 513

Champaign, Illinois 61820

Final Report

Approved for public release; distribution is unlimited.

Prepared for U.S. Army Installation Management Command (IMCOM) Headquarters Resource Efficiency Manager, G4 Energy, 2405 Gun Shed Road, Fort Sam Houston, Texas 78234-1223

Under MIPR 11268077 


\section{Abstract}

R-22 (also known as HCFC-22) is one of the most widely used refrigerants in U.S. Army air-conditioning and refrigeration (AC\&R) systems since the phase-out of R-12 refrigerant in 1995. The need to phase out R-22 is attributed to its global warming potential and high ozone-depleting capability. The U.S. Army has tens of thousands of aging AC\&R systems that will remain dependent on R-22, or one of the recently developed substitutes for R-22, until they reach the end of their operational life.

This project conducted a survey to understand the current R-22 usage and types of R-22 AC\&R equipment that are in use across U.S. Army Installation Management Command (IMCOM) installations. This study describes several methods to remove or retrofit R-22 from typical AC\&R equipment and implementation strategies to meet the stated goal of eliminating R-22 from IMCOM installations. The scope of this project included the review of BUILDER SMS data for IMCOM installations, which included data on 13,000 pieces of comfort cooling equipment for 31 installations. The report also provides an analysis of several R-22 alternatives and their physical properties and compatibility. Mission critical tactical cooling that uses R22 refrigerant was not within the scope of this project.

DISCLAIMER: The contents of this report are not to be used for advertising, publication, or promotional purposes. Citation of trade names does not constitute an official endorsement or approval of the use of such commercial products. All product names and trademarks cited are the property of their respective owners. The findings of this report are not to be construed as an official Department of the Army position unless so designated by other authorized documents.

DESTROY THIS REPORT WHEN NO LONGER NEEDED. DO NOT RETURN IT TO THE ORIGINATOR. 


\section{Contents}

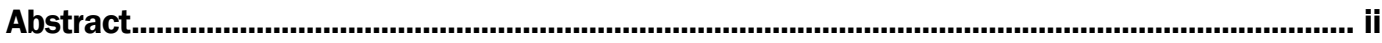

Figures and Tables........................................................................................................................................

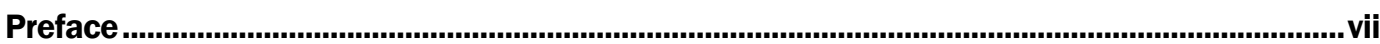

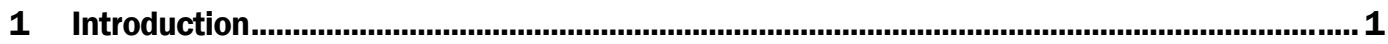

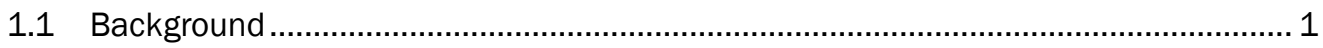

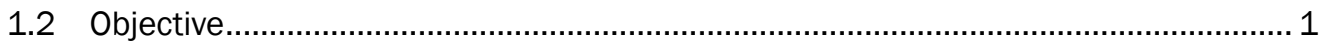

1.3 Scope.

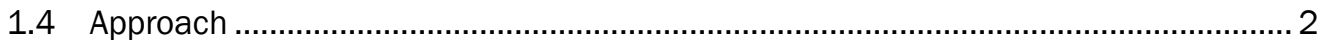

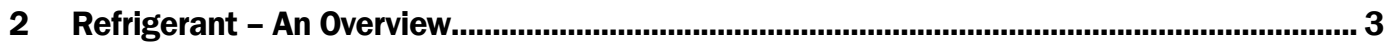

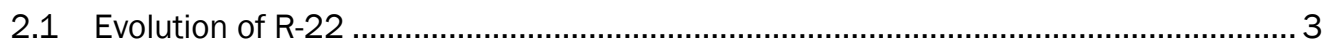

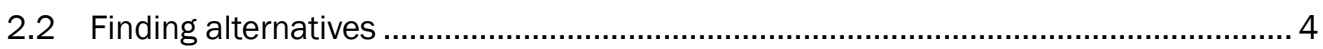

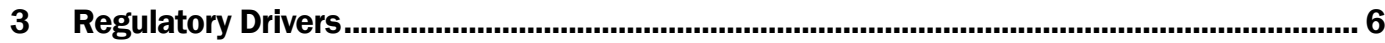

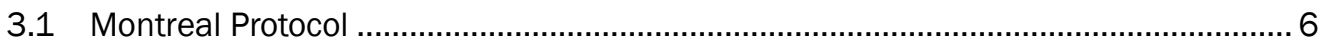

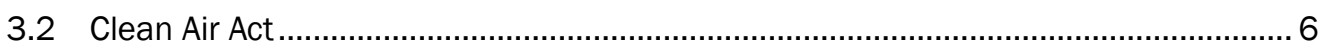

3.2.1 Section 608 ......................................................................................................... 7

3.2.2 USEPA's Significant New Alternatives Policy (SNAP) program....................................... 7

3.3 U.S. Department of Defense Policy and ODS Reserve .............................................. 7

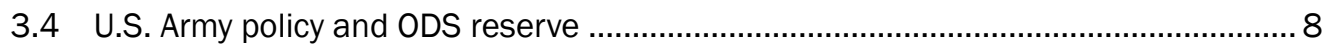

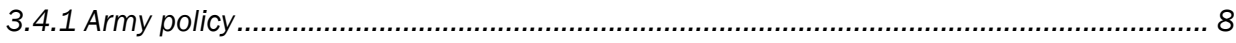

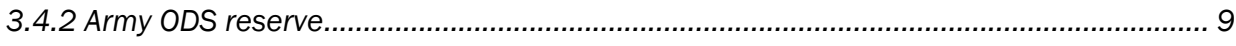

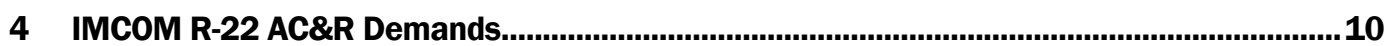

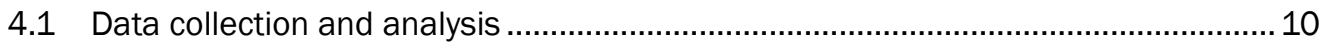

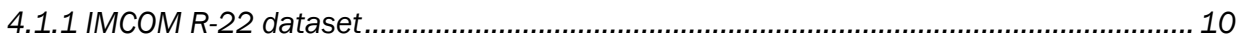

4.1.2 BUILDER equipment data ................................................................................ 11

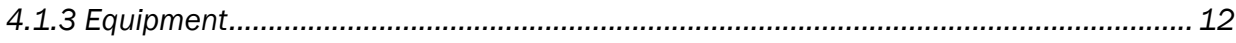

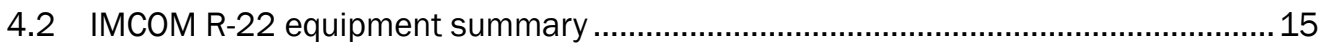

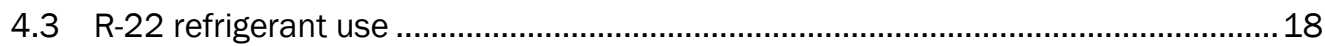

4.4 Calculation of R-22 refrigerant use .............................................................. 18

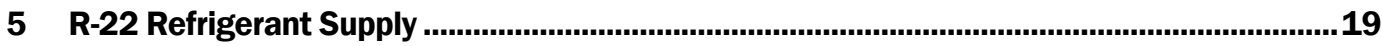

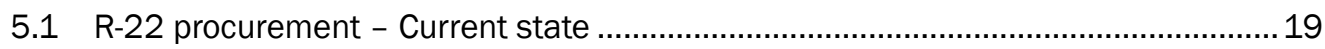

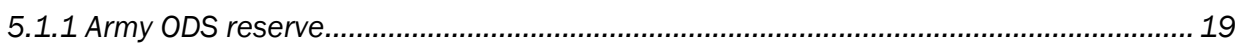

5.1.2 Commercial and General Service Administration (GSA) sources .................................19

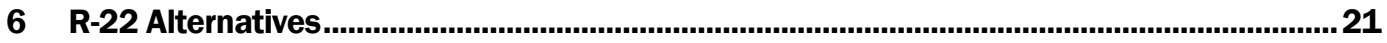

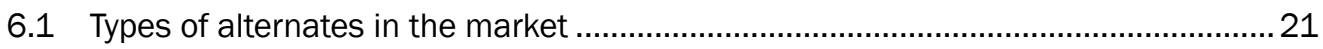

6.2 Considerations for selecting the appropriate alternative ........................................2 22

6.2.1 Recommendations for refrigeration systems ........................................................... 23

6.2.2 Recommendations for comfort cooling equipment ..................................................... 23

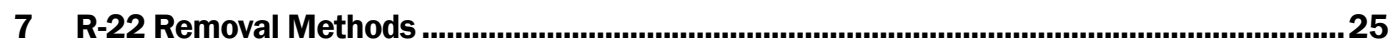

7.1 Method 1. Retrofit existing equipment with alternative refrigerant ..........................25 
7.2 Method 2. Replace the compressor ...................................................................26

7.3 Method 3. Replace EOL condensing equipment.................................................. 27

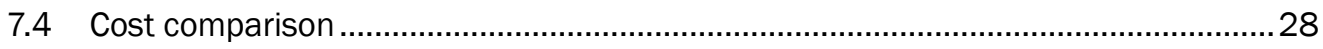

7.5 Life-Cycle Cost Analysis (LCCA) case study.....................................................29

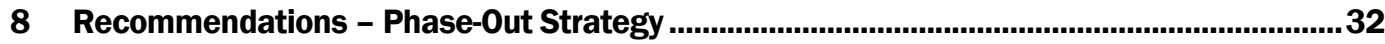

8.1 Method 3. Replace condensing equipment at EOL - Recommended method.

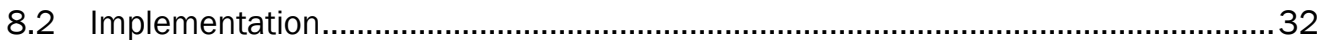

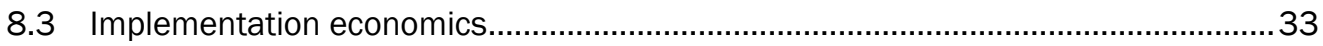

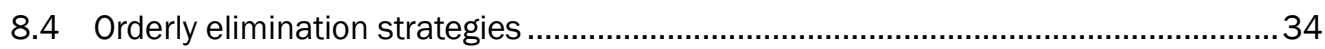

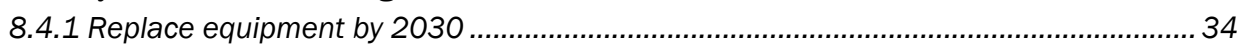

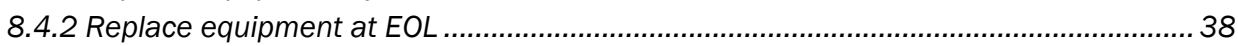

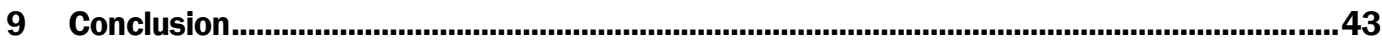

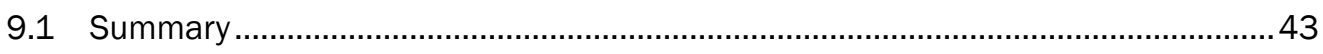

9.2 Path forward - Future technologies ............................................................. 44

References..................................................................................................................................46

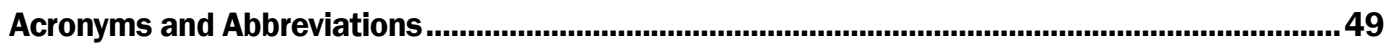

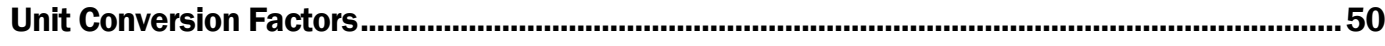

Appendix A: IMCOM BUILDER Data ........................................................................................51

Appendix B: Alternative Refrigerants and Retrofit Considerations .............................................54

Appendix C: Discussion of R-22 Elimination Methods and Procedures........................................62

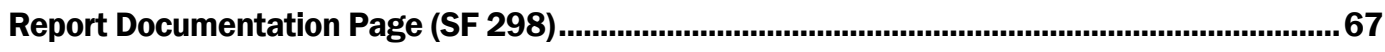




\section{Figures and Tables}

\section{Figures}

Figure 8-1. Cost comparison for condenser equipment replacement per category.

Figure 8-2. Replace R-22 equipment by 2030 ............................................................................ 38

Figure 8-3. Replace R-22 equipment by EOL. .................................................................................... 38

\section{Tables}

Table 3-1. U.S. HCFC phase-out schedule.

Table 4-1. IMCOM installations included within the April 2020 BUILDER dataset. ......................................... 11

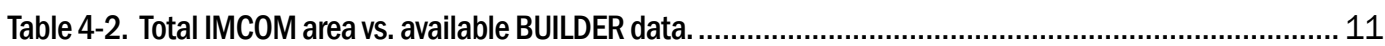

Table 4-3. Equipment types found in IMCOM BUILDER data................................................................. 13

Table 4-4. Average equipment age compared to ASHRAE expected service life.............................................. 14

Table 4-5. R-22 equipment inventory by equipment capacity for 30\% BUILDER data. ................................... 15

Table 4-6. Average BUILDER CRV by equipment type and capacity............................................................. 15

Table 4-7. R-22 equipment summary for 30\% BUILDER data. ................................................................ 16

Table 4-8. R-22 equipment extrapolation for 100\% BUILDER data. ......................................................... 16

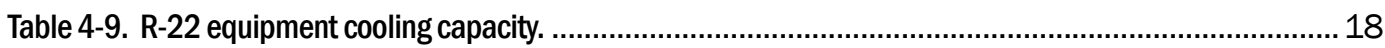

Table 4-10. R-22 refrigerant usage scenarios calculations. .................................................................... 18

Table 5-1. Rising cost of R-22.

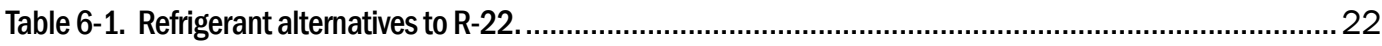

Table 7-1. Cost estimate for R-22 retrofit method................................................................................ 26

Table 7-2. Cost estimate for compressor replacement method. .................................................................... 27

Table 7-3. Cost estimate for condensing unit replacement.

Table 7-4. Cost estimates for recommended R-22 elimination methods......................................................... 28

Table 7-5. Results of 0 - to 5 -ton case study LCCA. ……...................................................................... 30

Table 8-1. Budgetary costs to eliminate R-22 by replacing condensing units.

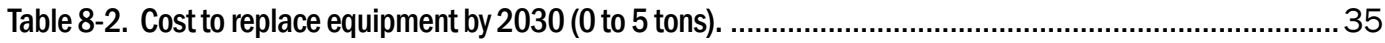

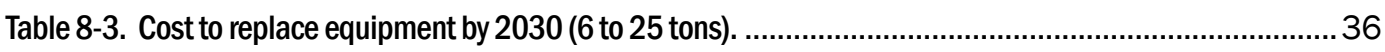

Table 8-4. Cost to replace equipment by 2030 ( 26 to 50 tons). ............................................................... 36

Table 8-5. Cost to replace equipment by 2030 (51 to 100 tons)........................................................... 37

Table 8-6. Cost to replace equipment by 2030 (101 tons \& above). ........................................................... 37

Table 8-7. Cost to replace equipment by EOL ( 0 to 5 tons). .................................................................. 39

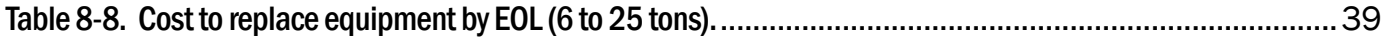

Table 8-9. Cost to replace equipment by EOL (26 to 50 tons)................................................................. 40

Table 8-10. Cost to replace equipment by EOL (51 to 100 tons). ................................................................ 41

Table 8-11. Cost to replace equipment by EOL (101 tons and above)............................................................ 42

Table A-1. BUILDER implementation status as of April 2020 ................................................................... 51

Table A-2. BUILDER implementation status based on building footage. .....................................................5

Table A-3. R-22 Equipment by IMCOM installation, based on capacity......................................................52 
Table B-1. List of commercially available R-22 alternative refrigerants. ..................................................... 54

Table C-1. Cost to retrofit existing equipment with alternative refrigerant.................................................... 65

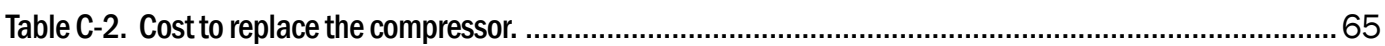

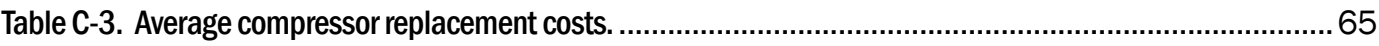

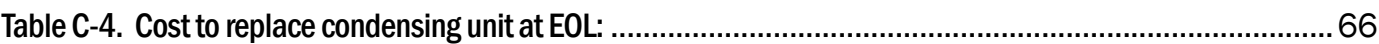




\section{Preface}

This study was conducted for the U.S. Army Installation Management Command (IMCOM) Headquarters Resource Efficiency Manager, G4 Energy under MIPR 11268077. The technical monitor was James Layne.

The work was performed by the Energy Branch, of the Facilities Division, U.S. Army Engineer Research and Development Center, Construction Engineering Research Laboratory (ERDC-CERL) At the time of publication, Mr. Jedediah Alvey was Chief of the Energy Branch; Ms. Vernessa Noye was Acting Chief of the Facilities Division; and Mr. Kurt Kinnevan was the Technical Director for Installations and Senior Scientific Technical Manager. The Acting Deputy Director of ERDC-CERL was Dr. George Calfas and the Interim Director was Dr. Kirankumar V. Topudurti.

COL Teresa A. Schlosser was Commander of ERDC, and Dr. David W. Pittman was the Director. 
THIS PAGE INTENTIONALLY LEFT BLANK 


\section{Introduction}

\subsection{Background}

R-22 (also known as HCFC-22) is one of the most widely used refrigerants in Army air-conditioning and refrigeration (AC\&R) systems since the phase-out of R-12 refrigerant in 1995. The need to phase out R-12 was attributed to its global warming potential and high ozone-depleting capability. However, in 1990, R-22 was listed as an ozone-depleting substance (ODS) due to its high global warming potential (GWP), and also subsequently underwent phase-out. In 2010, production and import of R-22 equipment was prohibited. As of o1 January 2020, all production of R-22 in the United States and its import into the country has officially ceased. Since that time, only the inventory of existing unused R-22 and recycled $\mathrm{R}-22$, recovered from cooling equipment, will be available for use in facility heating, ventilating, and air-conditioning (HVAC) and refrigeration equipment. While stockpiles of R-22 refrigerants will likely be available for this purpose, the costs of this product will become prohibitively expensive as time passes. As the cost of R-22 increases and the equipment using it continues to age, it may be necessary to research available alternatives to R-22, including suitable replacement or alternative refrigerants, along with other methods to reduce usage of R-22 within the Army.

The U.S. Army has tens of thousands of aging AC\&R systems that will remain dependent on R-22, or one of the recently developed substitutes for $\mathrm{R}-22$, until they reach the end of their operational life. The Army understands the need to develop a strategy for an orderly phase-out of R-22 in cooling systems throughout its installations to minimize and ultimately eliminate its dependence on R-22 refrigerants. The U.S. Army Corps of Engineers (USACE), Engineering Research and Development Center's, Construction Engineering Research Laboratory (ERDC-CERL) is supporting U.S. Army Installation Management Command (IMCOM) in this effort through this study by reviewing current R-22 usage, alternative refrigerants, and elimination methods.

\subsection{Objective}

The objective of this study is to develop a strategy for the orderly elimination of R-22 usage in Army AC\&R systems. The project also analyzes 
current R-22 usage, the availability of R-22 for facility use, viable alternative refrigerants, and elimination methods for Army facilities managed by IMCOM.

\subsection{Scope}

This study is solely focused on stationary equipment used for the purpose of comfort cooling and commercial refrigeration, which contain R-22 (HCFC-22) refrigerant within IMCOM facilities. Refrigerants in motor vehicle air-conditioning (MVAC), tactical environmental control units (ECUs), tactical weapon systems, laboratories, or other non-facility cooling systems are not included within the scope of this study.

\subsection{Approach}

To develop a strategy for the orderly elimination of R-22 within IMCOM installations, an understanding of the current environment had to be performed, along with the establishment of several parameters, and the collection of background data. The project team worked to collect data on the current inventory of operational R-22 AC\&R equipment (comfort cooling and refrigeration) deployed across IMCOM, as well as available R-22 resources, alternative refrigerants, and pertinent costs to develop elimination scenarios. From these scenarios, a phase-out strategy was developed to support IMCOM's efforts to remove R-22. 


\section{Refrigerant - An Overview}

Refrigerants such as R-22 and R-410A are the typical working fluids within AC\&R systems. Most AC\&R equipment operate with the application of a vapor-compression cycle, which requires a refrigerant to operate. The refrigerant transfers heat from one area, such as the interior conditioned space, and rejects the heat into another, such as the outdoors, usually by heat transfer through evaporation and condensation, respectively (ASHRAE 2018). A refrigerant is the main component of a modern refrigeration and air-conditioning equipment and its selection can impact the cost, safety, reliability, performance, and energy consumption of the cooling equipment.

\subsection{Evolution of R-22}

In 1928, Thomas Midgley, Albert Henne, and Robert McNary, of General Motors, synthesized the first chlorofluorocarbon (CFC) refrigerants. These compounds were the first non-flammable refrigeration fluids that improved the safety of air-conditioners, compared to ammonia $\left(\mathrm{NH}_{3}\right)$, which was typically used during this time (DoE 2015). Several different refrigerants were developed after this, which fell under the categories of CFCs (chlorofluorocarbons), HCFCs (hydrochlorofluorocarbons), and HFCs (hydrofluorocarbons). R-22, an HCFC, was one of the refrigerants that was developed during this period. Since R-22 was considered a safe and costeffective refrigerant choice, it became one of the standard refrigerants used in most cooling equipment for decades to come.

R-22 is a colorless fluid that contains chlorine atoms within its chemical structure. The inherent properties of chlorine, when released into the atmosphere, cause it to destroy or break down ozone particles, a process that is responsible for the depletion of the ozone layer. As the ozone layer decreases, the absorption of the sun's ultraviolet (UV) rays by the earth's atmosphere increases. Therefore, R-22 has both high ozone-depleting potential (ODP) and high GWP, which is why many nations have begun the process of eliminating R-22. Before HCFCs were banned, CFC compounds such as R-12 were also banned, for the same reasons. Though R-22 was thought to be less damaging than CFCs in the beginning, it was discovered that R-22 was damaging the ozone layer as well. The Montreal Protocol of 1987 outlined the phase-out of R-22 to begin in 2010 with its complete elimination in 2030. Chapter 3 further discusses the Montreal Protocol. 


\subsection{Finding alternatives}

As with the phase-out of CFC refrigerants, the AC\&R industry, with the looming ban of R-22, continued on their path to find more viable and reliable alternative refrigerants to replace HCFCs with refrigerants that cause fewer environmental concerns. The U.S. Environmental Protection Agency (USEPA) established the USEPA Significant New Alternatives Policy (SNAP) program in 1990 to evaluate substitutes for ODSs to reduce the overall risk to the environment. The USEPA SNAP program maintains a list of currently acceptable alternative refrigerants for each equipment type, such as chillers and air-conditioners. This list was cross-referenced as the basis for recommendations while developing a shortlist of safe alternatives for R-22. According to Notice 25 published by SNAP in 2014, there are over 50 acceptable substitutes for R-22, which include HFC blends, R22 derivatives, and other technologies. ${ }^{*}$

In addition, the management of greenhouse gases (GHGs) has encouraged the reduction of GWP emissions, which include refrigerants. The GWP metric was developed to allow comparisons of the global warming impacts of different gases. Specifically, it is a measure of how much energy the emissions of 1 ton of a gas will absorb over a given period of time, relative to the emissions of 1 ton of carbon dioxide $\left(\mathrm{CO}_{2}\right)$. As a reference, $\mathrm{R}-22$ has a GWP of 1,760, while R-12 has a GWP of 2,400 . It is recommended within the HVAC industry to set 2,000 as the upper GWP baseline.

One of the first alternatives to R-22 that the industry turned to were hydrofluorocarbons, or HFCs, which became popular in the refrigerant market. While HFCs are strong greenhouse gases with high GWP, they do not destroy the ozone. So, after the ban of R-22, HFCs gained popularity as potential alternatives. The typical HFC found in new supermarket cooling/refrigeration systems is R-410A. Additionally, several HFC refrigerant blends have been developed to reduce the ODP of existing refrigerants and to act as retrofits for existing R-22 equipment.

There are numerous new refrigerants currently in the marketplace, most of which are "blends." Blends combine existing refrigerants to develop a new refrigerant. Since the Montreal Protocol in 1987, manufacturers of refrigerants have researched new blends to reduce the ODP of existing

* EPA." Summary of substitute refrigerants listed in SNAP Notice 25." epa.gov, (2014). 
refrigerants, especially R-22. Chapter 6 and Appendix B include a deeper discussion of alternative refrigerants.

A survey of the SNAP regulations reveals that there is an uncertainty regarding R-22 alternatives as new findings from USEPA emerge. Currently, most new AC\&R equipment in the commercial market use R-410A. This will most likely be replaced with another refrigerant when R-410A enters the phase-out process. The R-22 phase-out should be approached with an awareness of this uncertainty in the regulations and the need for an advanced and permanent solution for all HVAC systems in the future. Since this consideration is beyond the scope of our study, we have included a summary of future recommendations at the end of this report. 


\section{Regulatory Drivers}

There are several regulatory drivers behind the elimination of ODSs and greenhouse gases from global use. This chapter gives a brief overview of the government regulations established to support the elimination of these substances, such as R-22.

\subsection{Montreal Protocol}

The Montreal Protocol on Substances that Deplete the Ozone Layer, an international agreement originally signed in 1987 and later adopted by 197 countries, including the United States, was initiated to eliminate ODS and limit damage to the ozone layer (U.S. Department of State 2020). The Protocol established a mandatory timeline for the orderly phase-out of ODSs, including refrigerants commonly used around the world, beginning in the late 1980 s through to complete elimination by 2030 .

The Protocol was initially concerned with CFCs, as their ODP was the greatest. Although HCFCs are ODSs and greenhouse gases, they were introduced as temporary replacements for CFCs because they are less potent at destroying stratospheric ozone than CFCs. But after several amendments and expansions through the late 1980s and 1990s, the Protocol was expanded to cover the elimination of HCFCs as well. These were categorized into two groups, Class I - CFCs, halons, carbon tetrachloride, and methyl chloroform; and Class II - HCFCs, which are compounds containing hydrogen, fluorine, chlorine, and carbon atoms. HCFCs are typically used as refrigerants, fire suppressants, and solvents. The later amendments to the Protocol from 1995 to 1997 established firm phase-out dates for developed and developing nations. These amendments also established the complete phase-out of Class I CFCs by 2000 and HCFCs by 2030.

\subsection{Clean Air Act}

Since the adoption of the Montreal Protocol, the USEPA has been contributing to the coalition and developing and implementing flexible, innovative, and effective approaches to support the Protocol's objectives within the United States (USEPA 2020a, b). To adhere to the Montreal Protocol phase-out timeline, the United States enacted legislation through the Clean Air Act, to establish policies and directives to support this. 
The U.S. Clean Air Act (CAA) is a federal law that defines USEPA's responsibilities for improving the nation's air quality and protecting the stratospheric ozone layer.

\subsubsection{Section 608}

Section 608 is a regulation within the CAA that codified the Montreal Protocol and supports its action to eliminate Class I and Class II ODS. U.S. reduction targets, listed in Table $3-1$, show the gradual reduction in HCFC production and consumption from baseline until $100 \%$ reduction in the year 2030.

Table 3-1. U.S. HCFC phase-out schedule.

\begin{tabular}{|l|l|l|l|}
\hline $\begin{array}{c}\text { Year to be } \\
\text { Implemented }\end{array}$ & \multicolumn{1}{|c|}{\begin{tabular}{c}
\multicolumn{1}{|c|}{ Implementation of HCFC Phase-out through CAA } \\
Regulations
\end{tabular}} & $\begin{array}{c}\text { Year to be } \\
\text { Implemented }\end{array}$ & $\begin{array}{c}\text { Percent Reduction in HCFC } \\
\text { Consumption and Production from } \\
\text { Baseline }\end{array}$ \\
\hline 2003 & No production or import of HCFC-141b & 2004 & $35.0 \%$ \\
\hline 2010 & $\begin{array}{l}\text { No production or import of HCFC-142b and HCFC-22, except } \\
\text { for use in equipment manufactured before 01 January 2010 }\end{array}$ & 2010 & $75.0 \%$ \\
\hline 2015 & $\begin{array}{l}\text { No production or import of any other HCFCs, except as } \\
\text { refrigerants in equipment manufactured before 01 January } \\
2020\end{array}$ & 2015 & $90.0 \%$ \\
\hline 2020 & No production or import of HCFC-142b and HCFC-22 & 2020 & $99.5 \%$ \\
\hline 2030 & No production or import of ANY HCFCs & 2030 & $100.0 \%$ \\
\hline Source: USEPA (2020a,b) & & \\
\hline
\end{tabular}

\subsubsection{USEPA's Significant New Alternatives Policy (SNAP) program}

As stated previously, the USEPA's SNAP program was established under Section 612 of the CAA of 1990) to identify and evaluate substitutes for ODSs (USEPA 2015). The USEPA SNAP program maintains a list of currently acceptable alternative refrigerants for each equipment type, such as chillers and air-conditioners. This list was cross-referenced as the basis for recommendations while developing a shortlist of safe alternatives for R-22 (refer to chapter 6).

\subsection{U.S. Department of Defense Policy and ODS Reserve}

After the international community's recognition of ODSs and the dangers that they posed, the U.S. Department of Defense (DoD) took action to ensure the availability of mission critical ODS, and to begin the reduction of ODS within the Military Services. Several memoranda and directives were set forth in the late 1980 os and early 1990 s to guide the path forward concerning the management of ODS within the DoD. 
One of the initial efforts was to establish a DoD ODS Reserve to support each of the Services and their mission needs with direction from the Under Secretary of Defense in 1992 and the Fiscal Year 1993 National Defense Authorization Act. This effort was tasked to the Defense Logistics Agency (DLA) to clarify ODS requirements of the individual Services and to establish an ODS reserve. This also included the development of plans to reclaim, recycle, and reuse ODS. Subsequently, DLA established the DoD ODS Reserve on 01 January 1994 at the Defense Depot Richmond Virginia, where they support each Service's ODS reserve account (DoA 2019).

The overarching driver behind the path forward concerning ODS is to seek alternative refrigerants to replace ODS, and also to ensure that there remain a sufficient supply of required ODS for mission critical uses for the years to come until viable and reliable alternatives are available.

\subsection{U.S. Army policy and ODS reserve}

\subsubsection{Army policy}

Army policies over the past 20 years have primarily focused on the general use reduction of ODS refrigerants while seeking viable alternatives and working to ensure adequate, and reliable stockpiles within its reserve. The drivers behind Army R-22 policies relate to the continued support for use reduction, the search for alternatives, and the stewardship of current R-22 supplies and mission critical R-22 systems, with emphasis on the capture of R-22 from non-tactical equipment into the Reserve (DoA 2008).

As the 2010 phase-out deadline approached, it was understood that R-22 supplies would become limited and that replacement refrigerants and the development of alternative tactical cooling systems were not viable. Therefore, the Army worked to reduce dependency on R-22 in areas where alternatives were viable, such as facility comfort cooling and refrigeration. Additionally, the Army established a policy to leverage the captured R-22 from these systems for use in mission critical tactical cooling. The Assistant Chief of Staff for Installation Management stated in his 2008 Memo (DoA 2008):

The Clean Air Act of 1990 implements an international production phaseout of R-22 beginning in 2010. The law also reduces demand for R-22 by prohibiting its use in new equipment after 2010 and directs the recovery of all refrigerants when AC\&R systems are serviced or retired. As Army installations service and replace aging air-conditioning and refrigeration 
units, the recovered R-22 not otherwise needed to meet installation requirements will be stockpiled to meet the future tactical need.

This approach will allow the Army to meet its goal of reduced use of R-22 through the gradual elimination of R-22 dependent AC\&R equipment within facilities, while providing an additional stream of R-22 into the Reserve to support mission critical tactical cooling.

The most recent memorandum from the Deputy Assistant Secretary for Acquisition Policy and Logistics in 2018 authorized the continued use of Class I and Class II ODS for deployed units to support weapon systems' cooling equipment, while alternatives are sought (DoA 2018a,b). The memorandum also stated that requisitions of ODS for non-Army weapon system applications are prohibited from the Army ODS Reserve. This updated guidance allows for the continued leveraging of ODS, as required for in-theater operations, while ensuring that the Army ODS Reserve is not diminished by non-mission critical demands.

The Army also established the Army ODS Elimination Program, with the stated mission to "Minimize the impact of ODS laws and regulations on the Readiness of the Army Warfighter by eliminating their dependency on Class I and Class II ODS" (DoA 2020). To date, the program has supported the elimination of Class I and II ODSs from Army installations, while working to find alternatives. The Army continues to field alternatives for all Class II ODS refrigerant applications with the goal of eliminating the use of HCFC refrigerants in facility AC\&R on all Army installations. The program continues to support tactical R-22 system requirements until they are eliminated.

\subsubsection{Army ODS reserve}

With the establishment of the DoD ODS Reserve, each Service has developed its own policies and directives concerning the management of mission critical ODS and their reserve account with DLA. The U.S. Army ODS Reserve is administered by the Army Environmental Support Office (ESO) (DoA 2019). The Army ODS Reserve supports all known R-22 mission critical weapon system requirements since its phase-out began in 2010 through conversion/replacement in 2030" (DoA 2019). 


\section{IMCOM R-22 AC\&R Demands}

\subsection{Data collection and analysis}

\subsubsection{IMCOM R-22 dataset}

To ascertain R-22 equipment and demand levels within IMCOM, a study of all R-22 AC\&R equipment in current operation was conducted. The project team worked with ERDC-CERL's BUILDER Sustainment Management System (BUILDER SMS) team to gather R-22 equipment data for IMCOM installations.

BUILDER SMS is a web-based software application developed by ERDCCERL to document, manage, and maintain DoD building assets and infrastructure. BUILDER SMS creates an inventory for each installation that manages data on every piece of equipment within a facility, including type, size, condition, age, performance, and replacement value to estimate the timeline for maintenance and repair. The BUILDER IMCOM R-22 dataset was collected by searching with the keyword "R-22," and all its pertinent derivations, to filter out only equipment that contain R-22 at installations where BUILDER has been implemented. As a result, the BUILDER SMS team was able to provide a dataset containing information on more than 13,00o pieces of HVAC equipment in sizes ranging from 1 to 800 tons for 31 IMCOM installations.

IMCOM is responsible for over 70 installations around the world, encompassing a footprint of approximately 734,966,513 sq ft. The supplied BUILDER SMS dataset provided information for approximately $30 \%$ of the 70 IMCOM installations, which included the 31 installations listed in Table 4-1. The BUILDER SMS team is working to implement BUILDER at all the IMCOM facilities, but as of April 2020, it has only been fully implemented at $29.9 \%$ of all IMCOM installations. Appendix A includes additional information regarding the BUILDER implementation status for each IMCOM installation. 
Table 4-1. IMCOM installations included within the April 2020 BUILDER dataset.

\begin{tabular}{|l|l|l|l|}
\hline 1. & Aberdeen Proving Ground & 17. & Fort Leonard Wood \\
\hline 2. & Carlisle Barracks & 18. & Fort Polk \\
\hline 3. & Dugway Proving Ground & 19. & Fort Riley \\
\hline 4. & Fort A P Hill & 20. & Fort Rucker \\
\hline 5. & Fort Belvoir & 21. & Fort Stewart \\
\hline 6. & Fort Benning & 22. & Joint Base Lewis-McChord \\
\hline 7. & Fort Bliss & 23. & Joint Base Myer-Henderson Hall \\
\hline 8. & Fort Bragg & 24. & Natick Soldier Systems Center \\
\hline 9. & Fort Campbell & 25. & Picatinny Arsenal \\
\hline 10. & Fort Carson & 26. & Redstone Arsenal \\
\hline 11. & Fort Detrick & 27. & U.S. Army Adelphi Laboratory Center \\
\hline 12. & Fort George G Meade & 28. & U.S. Army Garrison Stuttgart \\
\hline 13. & Fort Gordon & 29. & USAG Kwajalein Atoll \\
\hline 14. & Fort Hamilton & 30. & West Point Military Reservation \\
\hline 15. & Fort Hood & 31. & Yuma Proving Ground \\
\hline 16. & Fort Knox & & \\
\hline
\end{tabular}

Table 4-2 lists the square footage for both the assembled BUILDER data and the total IMCOM facility area. This BUILDER data (approx. 30\%) was analyzed and refined to determine the R-22 equipment levels across all of IMCOM by extrapolating the data based on the equipment information and square footage. This information was used to calculate R-22 equipment levels, refrigerant demand, and costs in later sections of this report.

Table 4-2. Total IMCOM area vs. available BUILDER data.

\begin{tabular}{|l|c|c|}
\hline Description & Area (sq ft) & $\begin{array}{c}\text { Percentage of } \\
\text { IMCOM Area }\end{array}$ \\
\hline Total IMCOM Area & $734,966,513$ & $100 \%$ \\
\hline Area of BUILDER Implementation as of April 2020 & $219,624,874$ & $29.9 \%$ \\
\hline
\end{tabular}

\subsubsection{BUILDER equipment data}

BUILDER SMS collects several pieces of information and metrics for each piece of equipment that characterize its current state. This dataset includes

1. Army Installation - where the equipment is located

2. Equipment make, model, and manufacturer information

3. ID number and serial number

4. Year of manufacture 
5. Year of installation

6. Equipment type

7. Capacity of the equipment

8. Remaining Service Life (RSL)

9. Condition Index (CI)

10. Component Replacement Value (CRV)

11. Control Type and location of the equipment within the installation (exterior or interior).

The assembled BUILDER SMS equipment dataset provided invaluable insight into the current inventory of over 13,000 pieces of R-22 equipment deployed across 31 IMCOM installations. Organized solely by IMCOM installation, the dataset required processing and refinement into a more manageable dataset before an analysis could occur. The refinement process leveraged several of the characteristics listed above to organize the equipment into parameters relevant to this study, including equipment type, capacity, and age.

\subsubsection{Equipment}

The following sections explain how these parameters helped frame strategies for the systematic and orderly elimination of R-22 from IMCOM facilities. Within the data there are varying categories of equipment characteristics that must be assessed while replacing each equipment type. However, this report acts as an overarching support document while phasing out R-22 in a facility. Since each equipment type is different, there must be additional analysis when a formal strategy is implemented.

The available equipment data from the BUILDER inventory, as it pertains to R-22 equipment, consists of several important equipment parameters. The following parameters were crucial to developing a strategy for the phase-out of R-22:

\subsubsection{Equipment type}

BUILDER data provided information on 13,375 pieces of various HVAC equipment that use R-22 equipment, which was estimated to account for approximately 30\% of the total IMCOM R-22 equipment. Upon analysis, we found out that the majority of the listed equipment fell into the categories (types) listed in Table 4-3. 
Table 4-3. Equipment types found in IMCOM BUILDER data.

\begin{tabular}{|l|c|}
\hline Equipment Type & $\begin{array}{c}\text { Count (For Available } \\
\text { Equipment Data) }\end{array}$ \\
\hline D302002 Furnaces* & 71 \\
\hline D303001 Chilled Water Systems & 490 \\
\hline D303002 Direct Expansion Systems & 3888 \\
\hline D304008 Air Handling Units* & 113 \\
\hline D305003 Fan Coil Units* & 174 \\
\hline D305006 Packaged Units & 8539 \\
\hline Totals: & 13275 \\
\hline * $\begin{array}{l}\text { These equipment types were listed as R-22 equipment in the } \\
\text { BUILDER dataset. It is noted that furnaces, air handling units, and } \\
\text { fan coil units contain R-22 in their pertinent condensing units. } \\
\text { However, it was assumed that the condensing units connected to } \\
\text { these equipment were accounted for within the dataset under one } \\
\text { of the other equipment types. Therefore, the furnace, air handling } \\
\text { unit, and fan coil unit equipment type numbers were removed from } \\
\text { our analysis in the later sections to reduce redundancy. }\end{array}$ \\
\hline
\end{tabular}

A large fraction of the equipment captured within the dataset are packaged units, which are outdoor units that provide multiple heating and cooling functions without any indoor furnace or air handling unit. By contrast, airhandling units and fan coil units primarily serve fan supply with an inbuilt heating/cooling element. Though the operational principle might be different for each type of equipment, R-22 is commonly used in condensing units, which is responsible for supporting the cooling cycle.

The BUILDER dataset did not contain information relating to commercial refrigeration systems. However, conversations with the facility engineers from the IMCOM installations revealed that few refrigeration systems currently use R-22. Most refrigeration systems have been replaced or retrofitted with new systems containing replacement refrigerants. Since accurate quantitative data were not available, we addressed refrigeration equipment from a literature review point of view in the later sections of the report.

\subsubsection{Year of installation}

Calculation of equipment age was based on the year of installation shown in the BUILDER dataset. Equipment age was used to determine the remaining operational or service life of the equipment. American Society of Heating, Refrigerating and Air-Conditioning Engineers (ASHRAE) data were referenced to calculate the expected operational life of each equipment type. This information and comparison with equipment service life 
allow for a replacement or retrofit analysis of the equipment, which is important for the life-cycle costing analysis and strategy development in later sections of this report. Table 4-4 lists average age of equipment in the inventory, based on BUILDER data and ASHRAE expected equipment service life, for comparison.

Table 4-4. Average equipment age compared to ASHRAE expected service life.

\begin{tabular}{|l|c|c|}
\hline Equipment Type & $\begin{array}{c}\text { Equipment Average } \\
\text { Age (year), } \\
\text { based on available } \\
\text { BUILDER Data }\end{array}$ & $\begin{array}{c}\text { Equipment } \\
\text { Expected Service } \\
\text { Life (year), based } \\
\text { on ASHRAE }\end{array}$ \\
\hline D303001 Chilled Water Systems & 17 & 20 \\
\hline D303002 Direct Expansion Systems & 16 & 20 \\
\hline D305006 Packaged Units & 13 & 15 \\
\hline Source: ASHRAE (2019) & \multicolumn{2}{|l}{} \\
\hline
\end{tabular}

Based on the available data, operational R-22 equipment at IMCOM facilities range in age from 1 to 80 years. Most of the listed equipment is younger than 15 years of age, which tracks with major equipment installations occurring just before the 2010 ban on installation of new R-22 equipment. The data indicated that some equipment was installed after 2010. While this may seem like an anomaly, there are several scenarios in which this equipment could have been installed subsequent to 2010. For one, installations may have purchased equipment in bulk before the end of 2010 and then installed when convenient or when an emergency equipment replacement was needed. In another scenario, some AC\&R manufacturers may have been allowed to continue selling R-22 systems as long as the compressors were charged with R-22 before the end of 2010, which would allow for their sale years after.

\subsubsection{Equipment capacity}

Equipment capacity refers to the ability of a heating or cooling system to heat or cool a given amount of space. Cooling capacity is expressed in tons (Table 4-5). This parameter is important because it is an important factor in determining the amount of refrigerant needed for the equipment's optimal performance. According to the manufacturer and trade organization data, optimal refrigerant capacity can range from 2 to 6 pounds (lbs.) per ton of equipment capacity. This lbs. per ton value is only one piece of the equation to determine the refrigerant charge (or amount of refrigerant needed) for a given piece of equipment. 
Table 4-5. R-22 equipment inventory by equipment capacity for $30 \%$ BUILDER data.

\begin{tabular}{|l|c|c|c|c|c|}
\hline \multirow{2}{*}{ Equipment Type } & \multicolumn{5}{|c|}{ Capacity } \\
\cline { 2 - 6 } & $\mathbf{0}$ to $\mathbf{5}$ tons & $\mathbf{6}$ to $\mathbf{2 5}$ tons & $\mathbf{2 6}$ to $\mathbf{5 0}$ tons & $\mathbf{5 1}$ to $\mathbf{1 0 0}$ tons & $\mathbf{1 0 1}$ tons \& above \\
\hline Chilled Water Systems & 4 & 75 & 144 & 166 & 101 \\
\hline Direct Expansion Systems & 2526 & 1199 & 117 & 35 & 11 \\
\hline Packaged Units & 7715 & 738 & 66 & 20 & - \\
\hline
\end{tabular}

This data provide an understanding of the R-22 demand across the assessed $30 \%$ of IMCOM facilities provided by the BUILDER dataset. This also allowed for some understanding of the equipment inventory and capacity ranges used to support appropriate selections for R-22 replacement methods and strategies. These data were then extrapolated to calculate the approximate R-22 demand and number of equipment items across all (or $100 \%)$ IMCOM facilities.

\subsubsection{Component replacement value (CRV)}

$\mathrm{CRV}$ is the cost of replacing equipment at its current state as established by BUILDER. This value is the calculated replacement cost of the equipment based on the cost per unit measured as specified in the standardized cost books, such as RS Means (Grussing 2012, ERDC-CERL 2019). Table 4-6 lists average BUILDER CRV by equipment type and capacity.

Table 4-6. Average BUILDER CRV by equipment type and capacity.

\begin{tabular}{|l|r|r|l|l|c|}
\hline Equipment Type & \multicolumn{1}{|l|}{ 0 to 5} & \multicolumn{1}{|c|}{$\mathbf{6}$ to 25} & $\mathbf{2 6}$ to 50 & 51 to 100 & 101 and above \\
\hline Chilled Water Systems & $\$ 16,697.43$ & $\$ 101,370.46$ & $\$ 107,758.03$ & $\$ 136,857.69$ & $\$ 255,047.97$ \\
\hline Direct Expansion Systems & $\$ 4,080.86$ & $\$ 8,469.41$ & $\$ 23,678.93$ & $\$ 48,850.58$ & $\$ 102,992.81$ \\
\hline Package Units & $\$ 12,740.18$ & $\$ 55,294.91$ & $\$ 112,843.18$ & $\$ 212,436.48$ & \\
\hline
\end{tabular}

CRV is a useful metric to determine replacement cost for each equipment type. The BUILDER CRV was compared against standardized equipment costs available in RS Means and available manufacturer data to ensure that these costs were relevant. A review determined that these values were applicable. Thus, they were used to calculate the cost of new replacement equipment in the phase-out strategies in chapter 8 of this report.

\subsection{IMCOM R-22 equipment summary}

The assembled BUILDER IMCOM dataset was analyzed and refined to estimate R-22 equipment levels across all of IMCOM by extrapolating the data 
based on the equipment information and square footage. Though there are equipment type and capacity variations across installations, the data are expected to normalize when considered across all of IMCOM and are intended to only provide budgetary figures. This approach allowed for the estimation of R-22 equipment and demand across IMCOM (Tables 4-7 and 4-8).

Table 4-7. R-22 equipment summary for 30\% BUILDER data.

\begin{tabular}{|c|c|c|c|}
\hline Equipment Type & $\begin{array}{c}\text { Average } \\
\text { Age (Years) }\end{array}$ & $\begin{array}{l}\text { No. Below Equipment } \\
\text { Operational Life (EOL) }\end{array}$ & $\begin{array}{l}\text { No. Beyond Equipment } \\
\text { Operational Life (EOL) }\end{array}$ \\
\hline \multicolumn{4}{|c|}{ Chilled Water Systems (ASHRAE Equipment Operational Life (EOL) - 20 years) } \\
\hline 0 to 5 tons & 16 & 4 & 0 \\
\hline 6 to 25 tons & 16 & 53 & 22 \\
\hline 26 to 50 tons & 16 & 132 & 12 \\
\hline 51 to 100 tons & 17 & 134 & 32 \\
\hline 101 tons \& above & 18 & 73 & 28 \\
\hline \multicolumn{3}{|l|}{ Sub-Total: } & 490 \\
\hline \multicolumn{4}{|c|}{ Direct Expansion Systems (ASHRAE Equipment Operational Life (EOL) - 20 years) } \\
\hline 0 to 5 tons & 16 & 2,038 & 488 \\
\hline 6 to 25 tons & 16 & 939 & 260 \\
\hline 26 to 50 tons & 17 & 95 & 22 \\
\hline 51 to 100 tons & 19 & 17 & 18 \\
\hline 101 tons $\&$ above & 16 & 10 & 1 \\
\hline \multicolumn{3}{|l|}{ Sub-Total: } & 3,888 \\
\hline \multicolumn{4}{|c|}{ Package Units (ASHRAE Equipment Operational Life (EOL) - 15 years) } \\
\hline 0 to 5 tons & 14 & 5,520 & 2,195 \\
\hline 6 to 25 tons & 14 & 429 & 390 \\
\hline 26 to 50 tons & 13 & 46 & 20 \\
\hline 51 to 100 tons & 13 & 16 & 4 \\
\hline 101 tons $\&$ above & - & - & - \\
\hline \multicolumn{3}{|l|}{ Sub-Total: } & 8,620 \\
\hline \multicolumn{3}{|c|}{ Equipment Total for $30 \%$ of IMCOM: } & 12,998 \\
\hline
\end{tabular}

Table 4-8. R-22 equipment extrapolation for $100 \%$ BUILDER data.

\begin{tabular}{|l|c|c|c|}
\hline Equipment Type & $\begin{array}{c}\text { Average Age } \\
\text { (Years) }\end{array}$ & $\begin{array}{c}\text { No. Below Equipment } \\
\text { Operational Life (EOL) }\end{array}$ & $\begin{array}{c}\text { No. Beyond Equipment } \\
\text { Operational Life (EOL) }\end{array}$ \\
\hline Chilled Water Systems (ASHRAE Equipment Operational Life (EOL) - 20 years) \\
\hline 0 to 5 tons & 16 & 13 & 0 \\
\hline 6 to 25 tons & 16 & 177 & 73 \\
\hline
\end{tabular}




\begin{tabular}{|c|c|c|c|}
\hline Equipment Type & $\begin{array}{l}\text { Average Age } \\
\text { (Years) }\end{array}$ & $\begin{array}{l}\text { No. Below Equipment } \\
\text { Operational Life (EOL) }\end{array}$ & $\begin{array}{l}\text { No. Beyond Equipment } \\
\text { Operational Life (EOL) }\end{array}$ \\
\hline 26 to 50 tons & 16 & 440 & 40 \\
\hline 51 to 100 tons & 17 & 447 & 107 \\
\hline 101 tons \& above & 18 & 243 & 93 \\
\hline \multicolumn{3}{|l|}{ Sub-Total: } & 1,633 \\
\hline \multicolumn{4}{|c|}{ Direct Expansion Systems (ASHRAE Equipment Operational Life (EOL) - 20 years) } \\
\hline 0 to 5 tons & 16 & 6,793 & 1,627 \\
\hline 6 to 25 tons & 16 & 3,130 & 867 \\
\hline 26 to 50 tons & 17 & 317 & 73 \\
\hline 51 to 100 tons & 19 & 57 & 60 \\
\hline 101 tons \& above & 16 & 33 & 3 \\
\hline \multicolumn{3}{|l|}{ Sub-Total: } & 12,960 \\
\hline \multicolumn{4}{|c|}{ Package Units (ASHRAE Equipment Operational Life (EOL) - 15 years) } \\
\hline 0 to 5 tons & 14 & 18,400 & 7,317 \\
\hline 6 to 25 tons & 14 & 1,430 & 1,030 \\
\hline 26 to 50 tons & 13 & 153 & 43 \\
\hline 51 to 100 tons & 13 & 53 & 13 \\
\hline 101 tons \& above & - & - & - \\
\hline \multicolumn{3}{|l|}{ Sub-Total: } & 28,439 \\
\hline \multicolumn{3}{|c|}{ Equipment Total for $100 \%$ of IMCOM: } & 43,032 \\
\hline
\end{tabular}

The data have shown that there are quite a number of equipment items nearing or past their equipment operational life (EOL), as established by ASHRAE (2019). As discussed earlier, many of the R-22 units were installed near the 2010 R-22 equipment production ban and will require maintenance or replacement in the coming years. This information for both the $30 \%$ and $100 \%$ dataset was used to develop the following demand and elimination methods that support the recommended phase-out strategy.

Note that this information was assembled in April 2020. It is possible that some existing R-22 equipment may have been replaced before or after these data were assembled and may have not been removed from this BUILDER dataset. Additionally, not all installations have fully implemented BUILDER so this analysis may not account for all R-22 equipment. With these caveats, this dataset still provides a valuable estimate of $\mathrm{R}-22$ equipment currently in use. 


\section{$4.3 \quad \mathrm{R}-22$ refrigerant use}

\subsection{Calculation of R-22 refrigerant use}

R-22 refrigerant usage was calculated using available BUILDER R-22 equipment data and the reported cooling tonnage of condensing equipment, then multiplying those values by reported industry average refrigerant usage per ton of cooling. The averages of 2, 4, and $6 \mathrm{lbs}$. of refrigerant per ton of cooling were used to estimate R-22 usage for 30\% of IMCOM installations. This was then extrapolated to represent the total equipment tonnage of $100 \%$ of IMCOM (Tables 4-9 and 4-10).

Table 4-9. R-22 equipment cooling capacity.

\begin{tabular}{|l|c|}
\hline Description & $\begin{array}{c}\text { Equipment Cooling } \\
\text { Capacity (tons) }\end{array}$ \\
\hline Total tonnage of R-22 condensing equipment in BUILDER dataset (Approx. 30\% of total IMCOM) & $1,010,774$ \\
\hline Extrapolated tonnage of R-22 condensing equipment for 100\% of IMCOM & $3,369,247$ \\
\hline
\end{tabular}

Table 4-10. R-22 refrigerant usage scenarios calculations.

\begin{tabular}{|l|c|c|}
\hline R-22 Refrigerant Demand Scenarios Calculations & $\begin{array}{c}\text { 30\% of IMCOM } \\
\text { (Ibs.) }\end{array}$ & $\begin{array}{c}\text { 100\% of } \\
\text { IMCOM } \\
\text { (Ibs.) }\end{array}$ \\
\hline Scenario 1: R-22 Refrigeration usage at average of 2lbs. per ton of cooling & $2,021,548$ & $6,738,493$ \\
\hline Scenario 2: R-22 Refrigeration usage at average of 4lbs. per ton of cooling & $4,043,096$ & $13,476,987$ \\
\hline Scenario 3: R-22 Refrigeration usage at average of 6lbs. per ton of cooling & $6,064,644$ & $20,215,480$ \\
\hline
\end{tabular}

The average R-22 usage calculations provide an estimate of useful R-22 that can be captured during the R-22 phase-out procedures. Considering the average scenario of $4 \mathrm{lbs}$. per ton, an approximate volume of $13,476,987$ pounds of R-22 refrigerant is currently being used by condensing equipment across IMCOM, as of April 2020. Therefore, there is a potential of recapturing a percentage of this volume of R-22 through standardized and approved USEPA ODS capture procedures, which can be used to maintain AC\&R equipment on-site or which can be transferred to the Army ODS Reserve. 


\section{$5 \quad$ R-22 Refrigerant Supply}

As a part of the Montreal Protocol, the United States has incrementally decreased the production and consumption of HCFCs with the aim to achieve a complete HCFC phase-out by 2030. R-22 is one of the most-used HCFCs in the market and the most common refrigerant for all equipment installed before 2010. After 2010, per the Montreal Protocol and CAA, no new equipment containing R-22 in its compressors is to be manufactured. R-22 production and import was also banned after January 2020.

\subsection{R-22 procurement - Current state}

To provide relevant recommendations to support the continued operation of AC\&R equipment through the years that it will take to reach complete $\mathrm{R}-22$ elimination, it was important to understand any logistical issues pertaining to R-22 availability experienced by installations. During the course of this study, the project team interacted with representatives from installations, commercial vendors, and Army officials to understand the current $\mathrm{R}-22$ procurement methods and recovery techniques.

\subsubsection{Army ODS reserve}

As discussed in chapter 3 of this report, the Army has established an R-22 reserve within the DLA-managed DoD ODS Reserve. Army regulations have established that R-22 currently held within the reserve is to support mission critical tactical cooling. Therefore, procurement of R-22 for nonmission critical AC\&R usage is prohibited and the Reserve is not a viable source for IMCOM installations.

\subsubsection{Commercial and General Service Administration (GSA) sources}

When interviewed, installation representatives indicated that they have been able to leverage commercial suppliers for purchase of R-22 refrigerant through GSA Schedule approved contractor vendors. Currently, acquisition through the GSA Schedule is the only viable means to procure R-22 refrigerant for facility AC\&R purposes. These representatives stated that, to date, they have not encountered any issues with this procurement process.

With consideration of future R-22 supplies, both commercial suppliers and the Army ODS Reserve project that sufficient stockpiles of R-22 will remain into the foreseeable future. This is due to the fact that sufficient stockpiles of 
new R-22 was produced before 2010, and the continued restock of recycled $\mathrm{R}-22$ captured from decommissioning existing R-22 equipment.

Several commercial R-22 suppliers were contacted to discuss costs and to evaluate the availability of future supplies. Vendors stated that costs of commercial acquisition are dependent on the scale of the purchase and the demand for the product at that time. The data in Table 5-1 indicate that costs per pound of R-22 have nearly doubled over the past 5 years. It can be expected that if demand rises and supplies diminish, costs will rise above the currently listed pricing.

Table 5-1. Rising cost of R-22.

\begin{tabular}{|r|c|}
\hline Cost of R-22 in 2014 & \$6-\$10 per pound \\
\hline Cost of R-22 in 2019 & \$16-\$20 per pound \\
\hline
\end{tabular}

Unit pricing was obtained from commercial refrigerant vendors and contractors in September 2020. Pricing can vary based on quantity, location, and time of purchase. 


\section{$6 \quad$ R-22 Alternatives}

The phase-out of R-22 has been in process for several decades, with the AC\&R industry working to prepare for the 2020 production and import ban. As such, several alternative refrigerants have been developed to operate as substitutes. A simple search of the market yields a long list of alternative refrigerants and refrigerant blends that claim to be either "drop in" or completely compatible retrofit options for existing R-22 equipment. It is known if many of these blends actually meet their compatibility claims.

In this study, several common blends that are available in the market were reviewed and down selected into recommendations for use in Army equipment. The study used the USEPA SNAP list of approved alternative refrigerants as the steppingstone for the analysis. The USEPA SNAP list includes over 50 acceptable substitutes for R-22, which include HFC blends, $\mathrm{R}-22$ derivatives, and other technologies. This list was cross-referenced as the basis for recommendations of safe alternatives for R-22 along with the following parameters to guide our research:

1. The alternate should be compatible with the existing equipment.

2. The alternate should result in minimum capacity losses.

3. The alternate should be compatible with USEPA regulations.

\subsection{Types of alternates in the market}

Several R-22 alternatives in the commercial market have been developed to serve either as "drop in" refrigerants or retrofit options. "Drop in" refrigerant is a term that has been used to describe a substitute or alternative refrigerant that can be added to an existing system with little or no modification, or to "top off" an existing system's current refrigerant charge with a different refrigerant. The USEPA, along with refrigerant and compressor manufacturers, do not recommend drop in solutions as a viable alternative. In fact, some combinations can cause permanent damage to the AC\&R system, including but not limited to compressors, seals, and valves. Appendix B includes additional information on alternative refrigerants.

In an attempt to suggest the most viable alternative refrigerants, an analysis was completed concerning the physical properties and characteristics of HFC alternatives and R-22 blends currently available on the market (Table 6-1). The analysis reviewed and compared various physical 
properties, compatibility, and GWP. The result of the analysis showed that $\mathrm{R}-407 \mathrm{C}$ and $\mathrm{R}-438 \mathrm{~A}$ were the two most viable alternative refrigerants available. Both alternatives are R-32 based refrigerant blends with zero ODP, relatively low GWP, and better compatibility. The composition of R407C and R-438A refrigerants have been designed to provide performance comparable to R-22, in terms of both capacity and energy efficiency. As a result, minimal system modifications are anticipated when retrofitting. Field experience has shown that R-407C and R-438A refrigerants will work successfully with the existing mineral (or alkylbenzene) oil in most systems. Appendix B discusses additional system considerations for retrofitting R-22 systems with R-407C and R-438A.

Table 6-1. Refrigerant alternatives to R-22.

\begin{tabular}{|c|c|c|c|c|c|c|c|c|c|}
\hline Refrigerant & $\begin{array}{c}\text { Commercial } \\
\text { Market } \\
\text { Name }\end{array}$ & GWP & ODP & $\begin{array}{c}\text { Oil } \\
\text { (lubricant) }\end{array}$ & $\begin{array}{l}\text { Relative } \\
\text { Capacity } \\
\text { (Baseline } \\
\text { = R22) }\end{array}$ & $\begin{array}{l}\text { Critical } \\
\text { Pressure } \\
\text { [MPa] }\end{array}$ & $\begin{array}{c}\text { Critical } \\
\text { Temperature } \\
\text { (F) }\end{array}$ & $\begin{array}{l}\text { Environmental } \\
\text { Classification }\end{array}$ & $\begin{array}{c}\text { Cost } \\
(\$ / \text { lbs. })\end{array}$ \\
\hline $\mathrm{R}-22$ & Freon & 1810 & 0.055 & Mineral Oil & $100 \%$ & 4.9 & 205.1 & HCFC & $\$ 17-20$ \\
\hline R-407C & $\begin{array}{c}\text { Genetron }{ }^{\circledR} \\
407 C\end{array}$ & 1774 & 0 & $\begin{array}{l}\text { Polyolester } \\
\text { (POE) oil }\end{array}$ & $95 \%$ & 4.6 & 186.8 & $\mathrm{HFC}$ & $\$ 5-6$ \\
\hline $\mathrm{R}-417 \mathrm{~A}$ & $\begin{array}{l}\text { ISCEON } \circledast \\
\text { MO59 }\end{array}$ & 2346 & 0 & POE & $85 \%$ & 4 & 188.7 & $\mathrm{HFC}$ & $\$ 5-8$ \\
\hline$R-422 B$ & $\begin{array}{c}\text { Freon NU- } \\
22 \mathrm{~B}\end{array}$ & 2525 & 0 & POE & $90 \%$ & 3.9 & 181.8 & $\mathrm{HFC}$ & $\$ 4-6$ \\
\hline $\mathrm{R}-422 \mathrm{D}$ & $\begin{array}{c}\text { ISCEON }{ }^{8} \\
\text { MO29 }\end{array}$ & 2729 & 0 & POE & $90 \%$ & 3.9 & 175.2 & $\mathrm{HFC}$ & $\$ 4-6$ \\
\hline R-438A & $\begin{array}{c}\text { ISCEON® } \\
\text { MO99 }\end{array}$ & 2265 & 0 & POE & $88 \%$ & 4.2 & 182.7 & HFC & $\$ 4-10$ \\
\hline
\end{tabular}

Interviews with contacts at Army installations conducted to determine their current R-22 elimination strategies revealed that they have been using alternative refrigerants, namely R-422B and R-417A, for their systems. Their use can be attributed to the variety of refrigerant blends available in the market and comparative performance between them. (Table 6-1 includes these refrigerants, for comparison.) Appendix B also discusses additional alternative blends.

\subsection{Considerations for selecting the appropriate alternative}

When selecting alternative refrigerants, parameters such as market availability, cost, the acceptability of the new refrigerant in existing systems, the reduction in capacity loss, and designated ASHRAE safety ratings were used to narrow the selections. Some of the selected refrigerants were R-407A, R- 
507A, and R-404A (for refrigerant replacement in refrigeration systems); and $\mathrm{R}-407 \mathrm{C}$ and $\mathrm{R}-438 \mathrm{~A}$ (for low to medium pressure compressors).

Refrigerant safety classifications were determined from ANSI/ASHRAE Standard 34 (ANSI/ASHRAE 2019). All refrigerants listed above are classified in Standard 34 as Safety Group A1, with low toxicity and zero flammability as defined by ASHRAE.

Compressors are lubricated with oil that mixes with the refrigerant and "travels" throughout the refrigerant system to provide lubrication, then returning to the compressor. Hence oil compatibility is very important when choosing a replacement refrigerant for R-22. R-22 requires the use of mineral oil; this type of oil is currently found in AC\&R systems that use R-22 and R-404A. The alternative refrigerants listed above, R-407A/C/F, R438A, and R-507A use polyolester (POE) oil, a synthetic oil that may not be compatible with all existing lubricant oils.

\subsubsection{Recommendations for refrigeration systems}

In existing low and medium temperature refrigeration systems, it is recommended to consider R-407A refrigerant for replacement of R-22. R$407 \mathrm{~A}$ is a non-ozone-depleting refrigerant with an ODP of zero and a GWP of 2,265. Another alternative, R-507A, is also a non-ozone-depleting refrigerant with an ODP of $\mathrm{o}$ and but has a higher GWP of 3,985. Consult the original compressor manufacturer for additional requirements before retrofitting existing refrigeration equipment. Appendix B includes additional information on alternative refrigerants.

\subsubsection{Recommendations for comfort cooling equipment}

In existing low and medium pressure R-22 refrigerant systems used for comfort cooling that incorporate hermetic, semi-hermetic, rotary, scroll, and screw compressors, it is recommended to consider using R-438A or R$407 \mathrm{C}$ refrigerants for replacement of $\mathrm{R}-22$. $\mathrm{R}-438 \mathrm{~A}$ is a non-ozone-depleting refrigerant with an ODP of zero and a GWP of 2,265. R-407C has an ODP of $O$ and GWP of 1,774. In most properly retrofitted systems, capacity should remain similar. Actual performance will depend on system design and operating conditions. During the retrofit, it is imperative to change the filter drier and critical elastomeric seals and gaskets. Consult the original compressor manufacturer for any additional requirements or 
recommendations. Appendix B includes additional information on alternative refrigerants.

For new or replacement air-conditioning or comfort cooling systems, it is recommended to purchase systems that use the above recommended refrigerants. Note that the future of refrigerants is constantly changing. Current research is focusing on non-ODSs and zero GWP, but these refrigerants and HVAC systems are not yet commercially viable. 


\section{$7 \quad$ R-22 Removal Methods}

$\mathrm{R}$-22 refrigerant is contained within the compressor, condenser, evaporator and connecting lines of AC\&R cooling systems. To eliminate the use of R-22 in these systems, either the equipment must be retrofitted to accommodate an alternate refrigerant or the existing unit can be replaced with a new system that is designed for use with currently acceptable refrigerants. following sections describe three methods that support the elimination of R-22 within Army AC\&R equipment.

Note that systems that contain R-22 refrigerant to condition mission critical facilities and spaces may need additional consideration when an installation is developing their individual phase-out strategy to determine the effects of AC\&R equipment replacement on these spaces and their functionality.

\subsection{Method 1. Retrofit existing equipment with alternative refrigerant}

The first method to eliminate R-22 from existing AC\&R equipment is to retrofit the system to accept an alternative refrigerant. Retrofitting is a procedure in which the refrigerant contained within the system is removed and certain system components are modified to accommodate a new refrigerant compound with different physical properties. An R-22 retrofit will come with its own challenges, which are further illustrated in Appendix $\mathrm{C}$, but the procedure is highlighted below.

The retrofitting procedure often involves system modification to accommodate alternate physical properties of the new refrigerant. Typically, modification is necessary to accommodate the new lubricating oil properties or different operating pressures. System modification includes the recovery of the R-22 refrigerant and mineral oil; replacement of the sight glass, filter drier, and thermal expansion valve for each circuit, and then recharging the system with an alternate refrigerant. This process and its complexity can vary depending on the type of compressor and the new refrigerant selected for installation. The structure of hermetically sealed compressors can make the units very complex to retrofit; in some cases, retrofit is not possible. A qualified technician should be consulted, or an engineering analysis should be completed to analyze each system before any retrofit procedure begins. 
The costs listed in Table 7-1 provide budgetary pricing for equipment retrofit procedures, based on refrigerant capacity. The costs were gathered from mechanical contractors for an estimate to retrofit AC equipment within the capacity ranges. However, the pricing can vary according to the type of equipment and complexity. The BUILDER dataset did not provide detailed information on compressor types for the listed equipment. As a result, retrofit costs were averaged across compressor types to calculate costs for all types of equipment in the dataset using the elimination method.

Table 7-1. Cost estimate for R-22 retrofit method.

\begin{tabular}{|l|c|c|}
\hline Equipment Capacity & Under 50 Tons & Above 51Tons \\
\hline Cost (\$) per ton of cooling & $\$ 300$ & $\$ 276$ \\
\hline Budgetary estimates from commercial contractors, September 2020 \\
\hline
\end{tabular}

Retrofitting existing equipment is an additional investment into the equipment before the end of its operational life. This procedure does not improve or extend the equipment's operational life. There are several system modifications that may actually create additional issues or decrease performance after the retrofit. These factors should be considered before choosing this course of action. Appendix $\mathrm{C}$ provides additional information on specific system modifications and retrofit procedures.

\subsection{Method 2. Replace the compressor}

Another method to eliminate the use of R-22 is to replace the existing compressor unit with a new compressor charged with an alternative refrigerant. As R-22 is primarily located inside the compressor and piping of a condensing unit, changing the compressor can be a viable option in many cases where retrofitting the equipment can be difficult. The new compressor can be recharged with an alternative refrigerant, thereby eliminating R-22.

The most common compressor types are scroll, screw, reciprocating, and rotary. Some of the reciprocating compressors can also be hermetic in design. As stated earlier, retrofitting hermetic compressors can be very difficult, therefore replacing them would be the preferred way to change the system to a new refrigerant.

As the BUILDER dataset did not provide detailed information on the compressor type, generalized costs were developed for the purchase and installation from standardized cost data books (RS Means 2010). These costs 
were developed by compressor capacity and are provided by cost per ton of cooling in Table 7-2.

Table 7-2. Cost estimate for compressor replacement method.

\begin{tabular}{|l|c|c|c|c|c|}
\hline Equipment Capacity & 0 to 5 Tons & 6 to 25 Tons & 26 to 50 Tons & 51 to 100 Tons & Above 101 Tons \\
\hline Cost $(\$)$ per ton of cooling & $\$ 1000-\$ 1200$ & $\$ 800-\$ 1000$ & $\$ 600-\$ 900$ & $\$ 300-\$ 600$ & $\$ 300-\$ 400$ \\
\hline RS Means (2010)
\end{tabular}

The provided costs are intended to serve as budgetary figures for the overall study. Without detailed specifications for each piece of equipment, averages for all types of compressors were derived based on capacity. The actual cost to replace a compressor will vary based the actual compressor type and size being replaced. An engineering analysis should be completed to analyze the existing equipment to develop a detailed replacement plan and budget before any retrofit procedure begins.

\subsection{Method 3. Replace EOL condensing equipment}

One of the most effective methods to eliminate R-22 refrigerant is to replace the existing equipment at the end of its operational or service life. According to ASHRAE, AC\&R equipment operational life expectancy is typically between 15 to 20 years for smaller cooling equipment (ASHRAE 2019). After this period, the equipment tends to perform poorly, break down, and offers low cooling efficiency. Replacing end-of-operational-life condensing equipment with new equipment will improve system energy efficiency, maintain system capacity, and provide a new operational life. Additionally, all new equipment manufactured after 2010 will come equipped with new acceptable refrigerants.

This elimination method is the most economical decision of the three presented, as the first two methods may not add or extend the life of the equipment but will involve additional system modifications. Although replacing the entire condensing unit may be initially more costly than just retrofitting the system, this approach will provide renewed efficiency and add more operating life to the entire system.

Costs for this method were calculated based on the CRV values provided in the BUILDER dataset. CRV is calculated through BUILDER by assessing the standardized equipment and labor costs to provide a reasonable cost estimate to replace the equipment in its current state. However, these costs 
can change based on the equipment condition at the time of replacement. Since BUILDER data is available to installation engineers, the CRV values can be accessed at any time to draft estimates for replacement. These costs are presented by equipment type and capacity in Table 7-3, where the listed cost is an average for equipment within that capacity range.

Table 7-3. Cost estimate for condensing unit replacement.

\begin{tabular}{|l|c|c|c|c|c|}
\hline Equipment Type & 0 to 5 Tons & 6 to 25 Tons & 26 to 50 Tons & 51 to 100 Tons & Above 101 Tons \\
\hline $\begin{array}{l}\text { Chilled Water } \\
\text { Systems }\end{array}$ & $\$ 16,697$ & $\$ 101,370$ & $\$ 107,758$ & $\$ 123,340$ & $\$ 255,048$ \\
\hline $\begin{array}{l}\text { Direct Expansion } \\
\text { Systems }\end{array}$ & $\$ 4,081$ & $\$ 8,469$ & $\$ 23,679$ & $\$ 29,475$ & $\$ 102,993$ \\
\hline Package Units & $\$ 12,740$ & $\$ 55,295$ & 112,843 & $\$ 212,436$ & $\begin{array}{l}\text { No Package Units } \\
\text { were found to be } \\
\text { above } 100 \text { tons }\end{array}$ \\
\hline BUILDER CRV data, April 2020 & & & & \\
\hline
\end{tabular}

\subsection{Cost comparison}

The data from Tables 7-1, 7-2, and 7-3 above were used to calculate cost ranges for each equipment type based on their capacities. During this study, the team analyzed a vast amount of equipment data from the BUILDER dataset, but detailed information on the type of compressors was not provided, making it difficult to obtain detailed costing information. For example, the costs of the refrigerant retrofit method were developed from estimates for the respective equipment capacities by manufacturer and AC\&R installer estimates. As such, the pricing detailed in Table 7-4 represent budgetary ranges for each category. It is estimated that the costs of each method would lie within the ranges provided in Table 7-4. However, it is recommended that an engineering analysis be completed to generate a detailed replacement plan and budget before beginning any retrofit procedure.

Table 7-4. Cost estimates for recommended R-22 elimination methods.

\begin{tabular}{|c|c|c|c|c|c|}
\hline \multicolumn{6}{|c|}{ Method 1: Replace R-22 with Alternate Refrigerant Cost (\$ per ton of cooling) } \\
\hline Equipment Type & $\mathbf{0}$ to 5 Tons & $\mathbf{6}$ to 25 Tons & $\mathbf{2 6}$ to 50 Tons & $\mathbf{5 1}$ to 100 Tons & Above 101 Tons \\
\hline $\begin{array}{c}\text { Chilled Water } \\
\text { Systems }\end{array}$ & $\$ 1,500-4,500$ & $\$ 5,000-7500$ & $\$ 7,500-13,500$ & $\$ 13,500-27,000$ & $>\$ 27,000$ \\
\hline $\begin{array}{c}\text { Direct Expansion } \\
\text { Systems }\end{array}$ & $\$ 1,500-4,500$ & $\$ 5,000-7500$ & $\$ 7,500-13,500$ & $\$ 13,500-27,000$ & $>\$ 27,000$ \\
\hline Package Units & $\$ 1,500-4,500$ & $\$ 5,000-13,500$ & $\$ 7,500-13,500$ & $\$ 13,500-27,000$ & $>\$ 27,000$ \\
\hline
\end{tabular}




\begin{tabular}{|c|c|c|c|c|c|}
\hline \multicolumn{6}{|c|}{ Method 2: Replace R-22 Compressor (\$ per ton of cooling) } \\
\hline Equipment Type & 0 to 5 Tons & 6 to 25 Tons & 26 to 50 Tons & 51 to 100 Tons & Above 101 Tons \\
\hline $\begin{array}{l}\text { Chilled Water } \\
\text { Systems }\end{array}$ & $\$ 1,200-6,000$ & $\$ 5,000-25,000$ & $\$ 20,000-40,000$ & $\$ 50,000-70,000$ & $>\$ 60,000$ \\
\hline $\begin{array}{l}\text { Direct Expansion } \\
\text { Systems }\end{array}$ & $\$ 1,200-6,000$ & $\$ 5,000-25,000$ & $\$ 20,000-40,000$ & $\$ 50,000-70,000$ & $>\$ 60,000$ \\
\hline Package Units & $\$ 1,200-6,000$ & $\$ 5,000-25,000$ & $\$ 20,000-40,000$ & $\$ 50,000-70,000$ & $>\$ 60,000$ \\
\hline \multicolumn{6}{|c|}{ Method 3: Replace Entire Condensing unit ( $\$$ per piece of equipment) } \\
\hline Equipment Type & 0 to 5 Tons & 6 to 25 Tons & 26 to 50 Tons & 51 to 100 Tons & Above 101 Tons \\
\hline $\begin{array}{l}\text { Chilled Water } \\
\text { Systems }\end{array}$ & $\$ 16,697$ & $\$ 101,370$ & $\$ 107,758$ & $\$ 123,340$ & $\$ 255,048$ \\
\hline $\begin{array}{l}\text { Direct Expansion } \\
\text { Systems }\end{array}$ & $\$ 4,081$ & $\$ 8,469$ & $\$ 23,679$ & $\$ 29,475$ & $\$ 102,993$ \\
\hline Package Units & $\$ 12,740$ & $\$ 55,295$ & $\$ 112,843$ & $\$ 212,436$ & $\begin{array}{l}\text { No Package Units } \\
\text { were found to be } \\
\text { above } 100 \text { tons }\end{array}$ \\
\hline
\end{tabular}

The data in Table 7-4 indicate that Method 1 requires substantial investment to modify the existing system to accept a new refrigerant. Method 1 does not guarantee an increase in operational life of the existing equipment and might create additional issues depending on the system complexity and alternative refrigerant used. Method 2 involves replacing the existing compressor within the condensing unit, with a new compressor, charged with an alternative refrigerant. This procedure will add a new compressor but does not guarantee an extension of operational life for the overall condensing system. The approach outlined by Method 3, to operate existing R-22 equipment until it reaches its EOL and then replacing with new equipment, can provide an extended life of about 15 to 20 years. The capital investment for Method 3, as supported by the life-cycle costing analysis below, shows that it is actually the most economical path forward when compared to investments needed with Methods 1 and 2.

\subsection{Life-Cycle Cost Analysis (LCCA) case study}

To further analyze the economics of each method, several LCCA studies were performed using the U.S. Army Corps of Engineers' ECONPACK (Economic Analysis Package) software. A description of one such case study follows.

Equipment considered for this study is a 5-ton direct expansion (DX) AirCooled System with a rotary compressor installed in 2010, the initial cost of which was $\$ 5,097$. Alternatives considered for the study are: 
- Alternative 1 (Method 1) - Equipment installed in 2010 at \$5,097 and then retrofitted in 2021 to accommodate new refrigerant at a cost of $\$ 1,500$

- Alternative 2 (Method 2) - Equipment installed in 2010 at \$5,097 and then the compressor is replaced in 2021 at a cost of $\$ 1,200$

- Alternative 3 (Method 3) - Equipment installed in 2010 at \$5,097 and then replaced in 2029 at EOL at a cost of $\$ 5,097$.

The parameters used within the study:

- Base Year of Analysis (2010): this was used as most R-22 equipment was installed near this date.

- Type of analysis: Mission Requirement.

- Project Type: MILCON.

- Period of Analysis: 20 Years; this is EOL for DX systems.

- Discount Rate: $4.4 \%$ per national discount rates.

- Discounting Convention: End-of-Year.

Results of the study were presented in the form of Net Present Value (NPV). NPV is calculated by discounting the value of costs minus the benefits for each year over the study period for a total NPV. Because costs of each method were the prime focus of this study, secondary benefits, or other costs (e.g., energy performance and utility costs) were not included within the analysis. Table 7-5 tabulates the results of the study.

Table 7-5. Results of 0- to 5-ton case study LCC
\begin{tabular}{|ll|c|}
\hline Method & NPV \\
\hline 1. & Retrofit & $\$ 7,931$ \\
\hline 2. & Replace Compressor & $\$ 7,633$ \\
\hline 3. & Replace Condensing Unit at EOL & $\$ 5,522$ \\
\hline
\end{tabular}

Results of the case study show that Method 3, replacing the condenser at the end of its operational life, would be the most economic option. Retrofitting and replacing the compressor requires a considerable investment during its lifetime but does not contribute towards increasing its life expectancy. Therefore, running the equipment till end of its operational life and then replacing with new equipment would be the recommended method. Though the actual costs and NPV values might differ, results of the study are a representation of most equipment types presented in the BUILDER dataset. 
There are several added benefits and energy costs based on seasonal efficiency ratings (SEERs) of each equipment that might play a role in determining the life-cycle costs of equipment. Also, each equipment might operate uniquely based on the equipment type and maintenance schedules. Therefore, it is important to exclude those parameters to normalize the data and arrive at budgetary values. 


\section{Recommendations - Phase-Out Strategy}

\subsection{Method 3. Replace condensing equipment at EOL - Recommended method}

After analyzing the candidate R-22 elimination strategies, Method 3 (replace condensing unit) was shown to be the most viable option for all equipment categories. This method provides for several benefits over other methods listed and better supports the effort to eliminate R-22. Considering the current availability of R-22 for purchase through commercial channels in reasonable quantities and cost, it is recommended to continue operating existing R-22 equipment to maximize as much of their service life as possible until major repairs are needed, or until the equipment no longer functions properly.

As discussed previously, with this approach, when a major repair occurs or the equipment reaches the end of its operational life, the existing condensing equipment can be replaced with a new unit. When the condensing unit is replaced, the new unit will be charged with an alternative refrigerant, thusly eliminating R-22 use from this equipment. The new condenser will begin a new service life and warranty period from the day it is installed, providing an additional cost benefit over a longer period. Additionally, the R-22 from the old equipment can be captured for use in other R-22 equipment or may be sent to the Army ODS Reserves.

\subsection{Implementation}

To facilitate the orderly elimination of R-22 refrigerant and equipment, implementation strategies and scenarios were developed to determine the most appropriate path forward. Based on the analysis of BUILDER data, it was observed that $10 \%$ of R-22 equipment in IMCOM facilities are older than 20 years (as of year 2020). As each year passes, more equipment will reach or surpass its expected operational or service life and subsequently can be replaced with new equipment. This rate of aging equipment allowed for the development of the following two strategies, the complete elimination and replacement of R-22 equipment by 2030 , and the orderly replacement of equipment as it reaches its end of operational life. 


\subsection{Implementation economics}

With the understanding that the best path forward is the replacement of condensing equipment toward the end of its operational life, budgetary costs were calculated to implement the aforementioned strategies (Table $8-1)$. Replacement costs were calculated for the available $30 \%$ of the IMCOM installations, by using CRV and equipment data available in the BUILDER dataset. These costs were then extrapolated to cover $100 \%$ of IMCOM, which provide budgetary implementation costs for all IMCOM installations (refer to section 4.2).

Table 8-1. Budgetary costs to eliminate R-22 by replacing condensing units.

\begin{tabular}{|l|c|c|}
\hline Capacity & $\begin{array}{c}\text { Replacement Cost, 30\% of } \\
\text { IMCOM (BUILDER dataset) }\end{array}$ & $\begin{array}{c}\text { Replacement Cost, 100\% of } \\
\text { IMCOM (Extrapolated) }\end{array}$ \\
\hline 5-10 Tons & $\$ 108,665,531$ & $\$ 362,218,436$ \\
\hline 5-25 Tons & $\$ 58,565,251$ & $\$ 195,217,502$ \\
\hline 25-50 Tons & $\$ 25,735,233$ & $\$ 85,784,110$ \\
\hline 50-100 Tons & $\$ 25,754,857$ & $\$ 85,849,525$ \\
\hline Above 100 Tons & $\$ 26,897,266$ & $\$ 89,657,553$ \\
\hline Total & $\$ 245,618,138$ & $\$ 818,727,126$ \\
\hline
\end{tabular}

The data in Table 8-1 and the graph in Figure 8-1 illustrate the costs required to replace all R-22 AC\&R equipment in IMCOM installations. Approximately $30 \%$ of the IMCOM AC\&R equipment data was available through the BUILDER dataset. This costing data was used to calculate that IMCOM would invest $\$ 248,618,138$ to replace equipment at $30 \%$ of its installations. These costs were then used to extrapolate costs for equipment replacement across all IMCOM installations. It was calculated that IMCOM would invest approximately $\$ 818,727,127$ to replace all AC\&R equipment across its installations, thereby eliminating all R-22 refrigerants used for comfort cooling.

The above costs were calculated using CRV values (Table 7-3) multiplied by the respective number of equipment items in each category (Tables 4-7 and 4-8). As mentioned earlier in section 4.1.3.4, CRV values are the costs associated with replacing equipment based on standardized cost data. These values are only calculated for budgetary purposes and can vary greatly based on specific equipment types, labor based on location, and several other parameters. Individual engineering estimates for each installation should be developed while planning a facility-wide R-22 elimination plan. 
Figure 8-1. Cost comparison for condenser equipment replacement per category.

Overall Costs to Replace R-22 Equipment

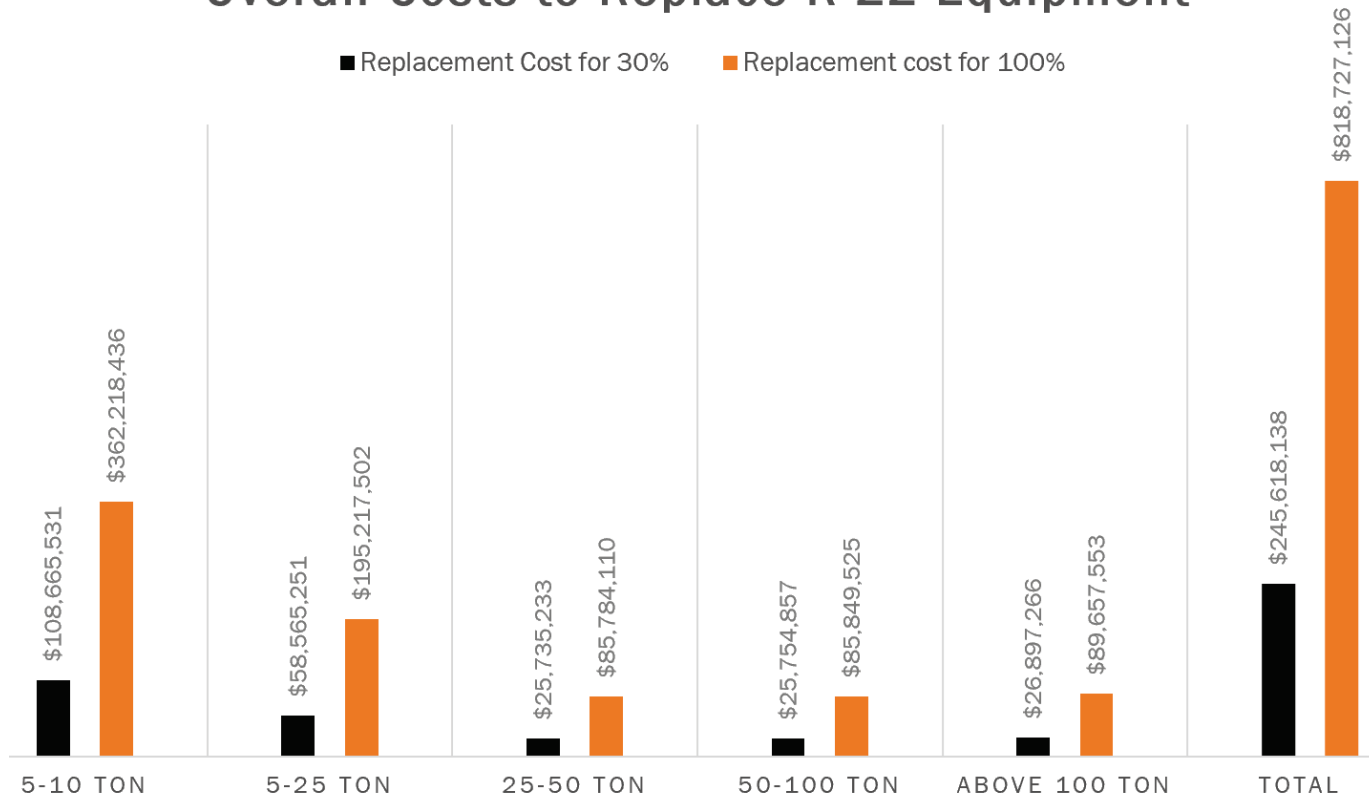

\subsection{Orderly elimination strategies}

To demonstrate an orderly elimination of R-22 equipment, the following strategies were developed to remove equipment as it reaches EOL. These strategies were framed using the available equipment data from 31 IMCOM installations as of April 2020, which is approximately 30\% of the entire IMCOM area. Note that some of this equipment may have already been replaced or retrofitted since many installations are actively working to remove R-22 equipment and reduce their dependency on this refrigerant. These strategies are provided to illustrate what an IMCOM-wide R-22 elimination process would look like in the future.

\subsubsection{Replace equipment by 2030}

This strategy recommends the replacement of all equipment before the year 2030 to completely eliminate the use of R-22 refrigerant in accordance with the Montreal Protocol and CAA phase-out. This approach recommends replacing $10 \%$ of the oldest equipment each year based on the age and retaining R-22 refrigerant for servicing remaining R-22 equipment. If each installation were to replace the oldest $10 \%$ of their equipment each year, IMCOM would annually invest $\$ 81,566,110.67$ beginning in 2021 until the complete removal of R-22 equipment is achieved in 2030 (Figure 8-2). 
Yearly budgetary costs were calculated from the available BUILDER dataset, i.e., $30 \%$ of the total IMCOM equipment to illustrate the yearly investment strategy. These costs were based on the available CRV within the BUILDER dataset.

Figure 8-2. Replace R-22 equipment by 2030.

Strategy 2: Replace Equipment Based on EOL

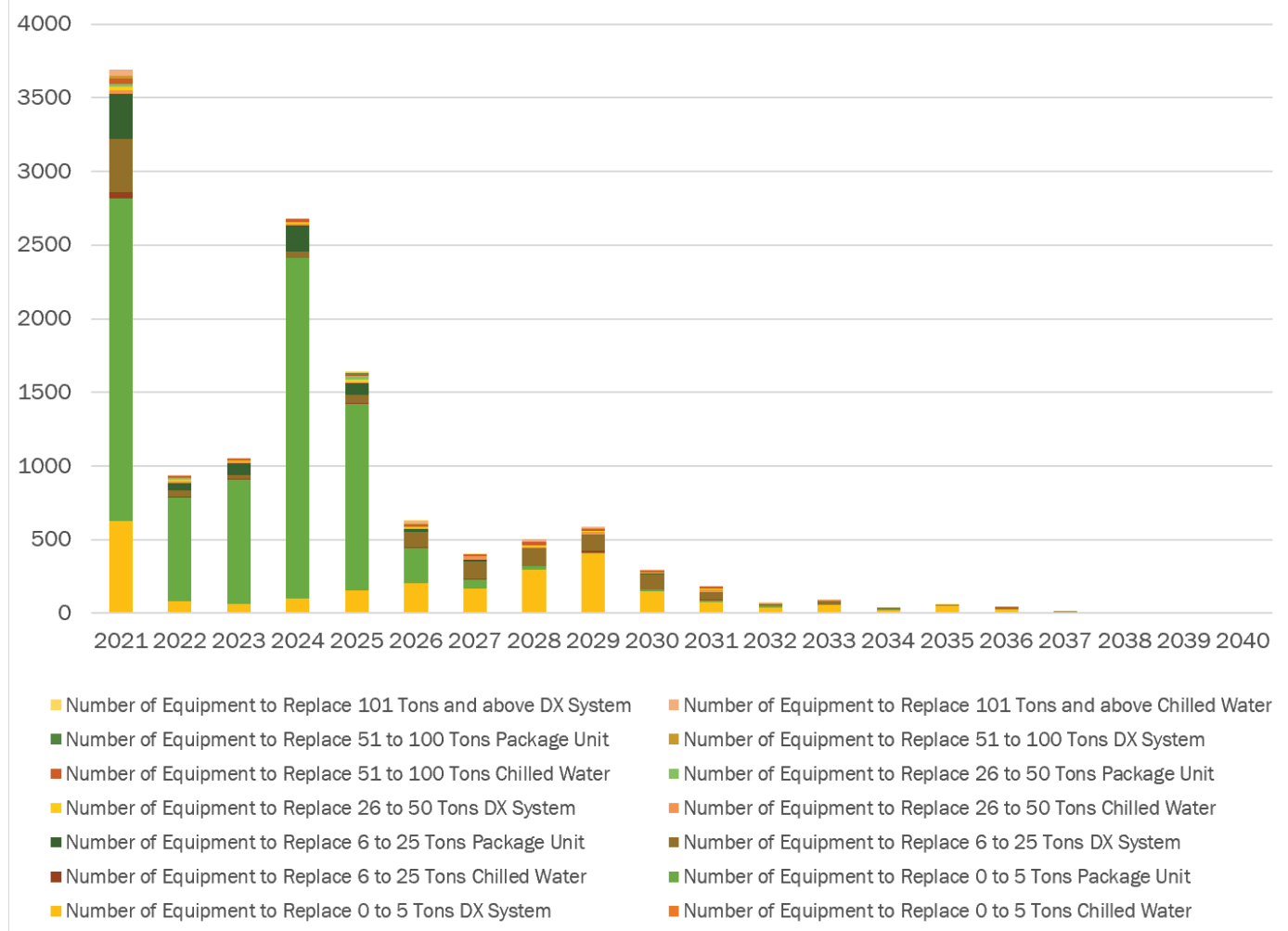

Tables 8-2 to 8-6 illustrate the annual expenditure if the Army moves to eliminate $10 \%$ of the equipment every year based on age. These calculations only consider equipment from the available 30\% of IMCOM BUILDER dataset.

Table 8-2. Cost to replace equipment by 2030 (0 to 5 tons).

\begin{tabular}{|c|c|c|c|c|c|c|c|}
\hline & \multicolumn{2}{|c|}{ Chilled Water System } & \multicolumn{2}{|c|}{ DX System } & \multicolumn{2}{|c|}{ Packaged Unit } & \multirow{2}{*}{ Total Replacement } \\
\cline { 2 - 7 } Year & $\begin{array}{c}\text { \# of } \\
\text { Equip }\end{array}$ & Cost (\$) & $\begin{array}{c}\text { \# of } \\
\text { Equip }\end{array}$ & Cost (\$) & $\begin{array}{c}\text { \# of } \\
\text { Equip }\end{array}$ & Cost (\$) & \begin{tabular}{c} 
Coar) \\
\hline 2021
\end{tabular} \\
\hline 2 & $16,697.43$ & 253 & $1,030,825.24$ & 772 & $9,829,048.87$ & $10,876,572$ \\
\hline 2022 & 1 & $16,697.43$ & 253 & $1,030,825.24$ & 772 & $9,829,048.87$ & $10,876,572$ \\
\hline 2024 & 1 & $16,697.43$ & 253 & $1,030,825.24$ & 772 & $9,829,048.87$ & $10,876,572$ \\
\hline 2025 & 0 & $16,697.43$ & 253 & $1,030,825.24$ & 772 & $9,829,048.87$ & $10,876,572$ \\
\hline 2026 & 0 & - & 253 & $1,030,825.24$ & 772 & $9,829,048.87$ & $10,876,572$ \\
\hline
\end{tabular}




\begin{tabular}{|c|c|c|c|c|c|c|c|}
\hline \multirow[b]{2}{*}{ Year } & \multicolumn{2}{|c|}{ Chilled Water System } & \multicolumn{2}{|c|}{ DX System } & \multicolumn{2}{|c|}{ Packaged Unit } & \multirow[b]{2}{*}{$\begin{array}{l}\text { Total Replacement } \\
\text { Cost (\$/year) }\end{array}$} \\
\hline & $\begin{array}{l}\text { \# of } \\
\text { Equip }\end{array}$ & Cost (\$) & $\begin{array}{c}\text { \# of } \\
\text { Equip }\end{array}$ & Cost (\$) & $\begin{array}{c}\text { \# of } \\
\text { Equip }\end{array}$ & Cost (\$) & \\
\hline 2027 & 0 & - & 253 & $1,030,825.24$ & 772 & $9,829,048.87$ & $10,876,572$ \\
\hline 2028 & 0 & - & 253 & $1,030,825.24$ & 772 & $9,829,048.87$ & $10,876,572$ \\
\hline 2029 & 0 & - & 253 & $1,030,825.24$ & 772 & $9,829,048.87$ & $10,876,572$ \\
\hline 2030 & 0 & - & 253 & $1,030,825.24$ & 772 & $9,829,048.87$ & $10,876,572$ \\
\hline Total: & 4 & $\$ 66,790$ & 2526 & $\$ 10,308,252$ & 7715 & $\$ 98,290,489$ & $\$ 108,665,531$ \\
\hline
\end{tabular}

Table 8-3. Cost to replace equipment by 2030 (6 to 25 tons).

\begin{tabular}{|c|c|c|c|c|c|c|c|}
\hline \multirow[b]{2}{*}{ Year } & \multicolumn{2}{|c|}{ Chilled Water System } & \multicolumn{2}{|c|}{ DX System } & \multicolumn{2}{|c|}{ Packaged Unit } & \multirow{2}{*}{$\begin{array}{c}\text { Total } \\
\text { Replacement Cost } \\
\text { (\$/year) }\end{array}$} \\
\hline & $\begin{array}{c}\text { \# of } \\
\text { Equip }\end{array}$ & Cost (\$) & $\begin{array}{c}\text { \# of } \\
\text { Equip }\end{array}$ & Cost (\$) & $\begin{array}{c}\text { \# of } \\
\text { Equip }\end{array}$ & Cost (\$) & \\
\hline 2021 & 8 & $810,963.68$ & 120 & $1,016,329.20$ & 74 & $4,091,823.34$ & $5,919,116$ \\
\hline 2022 & 8 & $810,963.68$ & 120 & $1,016,329.20$ & 74 & $4,091,823.34$ & $5,919,116$ \\
\hline 2023 & 8 & $810,963.68$ & 120 & $1,016,329.20$ & 74 & $4,091,823.34$ & $5,919,116$ \\
\hline 2024 & 8 & $810,963.68$ & 120 & $1,016,329.20$ & 74 & $4,091,823.34$ & $5,919,116$ \\
\hline 2025 & 8 & $810,963.68$ & 120 & $1,016,329.20$ & 74 & $4,091,823.34$ & $5,919,116$ \\
\hline 2026 & 8 & $810,963.68$ & 120 & $1,016,329.20$ & 74 & $4,091,823.34$ & $5,919,116$ \\
\hline 2027 & 7 & $709,593.22$ & 120 & $1,016,329.20$ & 74 & $4,091,823.34$ & $5,817,746$ \\
\hline 2028 & 7 & $709,593.22$ & 120 & $1,016,329.20$ & 74 & $4,091,823.34$ & $5,817,746$ \\
\hline 2029 & 7 & $709,593.22$ & 120 & $1,016,329.20$ & 73 & $4,036,528.43$ & $5,762,451$ \\
\hline 2030 & 6 & $608,222.76$ & 119 & $1,007,859.79$ & 73 & $4,036,528.43$ & $5,652,611$ \\
\hline Total: & 75 & $\$ 7,602,785$ & 1199 & $\$ 10,154,823$ & 738 & $\$ 40,807,644$ & $\$ 58,565,251$ \\
\hline
\end{tabular}

Table 8-4. Cost to replace equipment by 2030 (26 to 50 tons).

\begin{tabular}{|c|c|c|c|c|c|c|c|}
\hline \multirow[b]{2}{*}{ Year } & \multicolumn{2}{|c|}{ Chilled Water System } & \multicolumn{2}{|c|}{ DX System } & \multicolumn{2}{|c|}{ Packaged Unit } & \multirow[b]{2}{*}{$\begin{array}{c}\text { Total Replacement } \\
\text { Cost (\$/year) }\end{array}$} \\
\hline & $\begin{array}{l}\text { \# of } \\
\text { Equip }\end{array}$ & Cost (\$) & $\begin{array}{l}\text { \# of } \\
\text { Equip }\end{array}$ & Cost (\$) & $\begin{array}{l}\text { \# of } \\
\text { Equip }\end{array}$ & Cost (\$) & \\
\hline 2021 & 15 & $1,520,556.90$ & 12 & $284,136.00$ & 7 & $789,901.00$ & $2,594,594$ \\
\hline 2022 & 15 & $1,520,556.90$ & 12 & $284,136.00$ & 7 & $789,901.00$ & $2,594,594$ \\
\hline 2023 & 15 & $1,520,556.90$ & 12 & $284,136.00$ & 7 & $789,901.00$ & $2,594,594$ \\
\hline 2024 & 15 & $1,520,556.90$ & 12 & $284,136.00$ & 7 & $789,901.00$ & $2,594,594$ \\
\hline 2025 & 14 & $1,419,186.44$ & 12 & $284,136.00$ & 7 & $789,901.00$ & $2,493,223$ \\
\hline 2026 & 14 & $1,419,186.44$ & 12 & $284,136.00$ & 7 & $789,901.00$ & $2,493,223$ \\
\hline 2027 & 14 & $1,419,186.44$ & 12 & $284,136.00$ & 6 & $677,058.00$ & $2,380,380$ \\
\hline 2028 & 14 & $1,419,186.44$ & 11 & $260,458.00$ & 6 & $677,058.00$ & $2,356,702$ \\
\hline 2029 & 14 & $1,419,186.44$ & 11 & $260,458.00$ & 6 & $677,058.00$ & $2,356,702$ \\
\hline 2030 & 14 & 1,419,186.44 & 11 & $260,458.00$ & 6 & $677,058.00$ & $2,356,702$ \\
\hline
\end{tabular}




\begin{tabular}{|c|c|c|c|c|c|c|c|}
\hline & \multicolumn{2}{|c|}{ Chilled Water System } & \multicolumn{2}{|c|}{ DX System } & \multicolumn{2}{c|}{ Packaged Unit } & \\
\cline { 2 - 7 } Year & $\begin{array}{c}\text { \# of } \\
\text { Equip }\end{array}$ & Cost (\$) & $\begin{array}{c}\text { \# of } \\
\text { Equip }\end{array}$ & Cost (\$) & $\begin{array}{c}\text { \# of } \\
\text { Equip }\end{array}$ & Cost (\$) & $\begin{array}{c}\text { Total Replacement } \\
\text { Cost (\$/year) }\end{array}$ \\
\hline Total: & 144 & $\$ 14,597,346$ & 117 & $\$ 2,770,326$ & 66 & $\$ 7,447,638$ & $\$ 24,815,310$ \\
\hline
\end{tabular}

Table 8-5. Cost to replace equipment by 2030 (51 to 100 tons).

\begin{tabular}{|c|c|c|c|c|c|c|c|}
\hline & \multicolumn{2}{|c|}{ Chilled Water System } & \multicolumn{2}{|c|}{ DX System } & \multicolumn{2}{|c|}{ Packaged Unit } & \multirow{2}{*}{$\begin{array}{c}\text { Total } \\
\text { Replacement } \\
\text { Cost (\$/year) }\end{array}$} \\
\cline { 2 - 7 } Year & $\begin{array}{c}\text { \# of } \\
\text { Equip }\end{array}$ & Cost (\$) & $\begin{array}{c}\text { \# of } \\
\text { Equip }\end{array}$ & Cost (\$) & $\begin{array}{c}\text { \# of } \\
\text { Equip }\end{array}$ & Cost (\$) & 2,639,555 \\
\hline 2021 & 17 & $2,096,780.00$ & 4 & $117,901.72$ & 2 & $424,872.96$ & $2,639,555$ \\
\hline 2022 & 17 & $2,096,780.00$ & 4 & $117,901.72$ & 2 & $424,872.96$ & $2,639,555$ \\
\hline 2023 & 17 & $2,096,780.00$ & 4 & $117,901.72$ & 2 & $424,872.96$ & $2,516,215$ \\
\hline 2024 & 16 & $1,973,440.00$ & 4 & $117,901.72$ & 2 & $424,872.96$ & $2,639,555$ \\
\hline 2025 & 17 & $2,096,780.00$ & 4 & $117,901.72$ & 2 & $424,872.96$ & $2,610,079$ \\
\hline 2026 & 17 & $2,096,780.00$ & 3 & $88,426.29$ & 2 & $424,872.96$ & $2,610,079$ \\
\hline 2027 & 17 & $2,096,780.00$ & 3 & $88,426.29$ & 2 & $424,872.96$ & $2,486,739$ \\
\hline 2028 & 16 & $1,973,440.00$ & 3 & $88,426.29$ & 2 & $424,872.96$ & $2,486,739$ \\
\hline 2029 & 16 & $1,973,440.00$ & 3 & $88,426.29$ & 2 & $424,872.96$ & $2,486,739$ \\
\hline 2030 & 16 & $1,973,440.00$ & 3 & $88,426.29$ & 2 & $424,872.96$ & $\$ 25,754,810$ \\
\hline Total: & 166 & $\$ 17,887,828$ & 35 & $\$ 828,730$ & 20 & $\$ 2,256,860$ & $\$$ \\
\hline
\end{tabular}

Table 8-6. Cost to replace equipment by 2030 (101 tons \& above).

\begin{tabular}{|c|c|c|c|c|c|}
\hline \multirow[b]{2}{*}{ Year } & \multicolumn{2}{|c|}{ Chilled Water System } & \multicolumn{2}{|c|}{ DX System } & \multirow[t]{2}{*}{$\begin{array}{l}\text { Total Replacement } \\
\text { Cost (\$/year) }\end{array}$} \\
\hline & \# of Equip & Cost (\$) & \# of Equip & Cost (\$) & \\
\hline 2021 & 11 & $2,805,527.67$ & 2 & $205,985.62$ & $3,011,513.29$ \\
\hline 2022 & 10 & $2,550,479.70$ & 1 & $102,992.81$ & $2,653,472.51$ \\
\hline 2023 & 10 & $2,550,479.70$ & 1 & $102,992.81$ & $2,653,472.51$ \\
\hline 2024 & 10 & $2,550,479.70$ & 1 & $102,992.81$ & $2,653,472.51$ \\
\hline 2025 & 10 & $2,550,479.70$ & 1 & $102,992.81$ & $2,653,472.51$ \\
\hline 2026 & 10 & $2,550,479.70$ & 1 & $102,992.81$ & $2,653,472.51$ \\
\hline 2027 & 10 & $2,550,479.70$ & 1 & $102,992.81$ & $2,653,472.51$ \\
\hline 2028 & 10 & $2,550,479.70$ & 1 & $102,992.81$ & $2,653,472.51$ \\
\hline 2029 & 10 & $2,550,479.70$ & 1 & $102,992.81$ & $2,653,472.51$ \\
\hline 2030 & 10 & $2,550,479.70$ & 1 & $102,992.81$ & $2,653,472.51$ \\
\hline Total: & 101 & $\$ 25,759,845$ & 11 & $\$ 1,132,921$ & $\$ 26,892,766$ \\
\hline \multicolumn{6}{|c|}{$\begin{array}{l}\text { * Large equipment needs special attention and further investigation to understand the complexity of the } \\
\text { replacement procedure. Though we have provided budgetary costs for the replacement, the actual } \\
\text { process can be complex and therefore will require detailed engineering analysis for decision making. }\end{array}$} \\
\hline
\end{tabular}




\subsubsection{Replace equipment at EOL}

The second strategy that was developed to achieve elimination of R-22, specifies the replacement of equipment as they reach their end of operational life. This approach allows for the most orderly effort to eliminate R22, as compared to the previous strategy, while allowing for more equipment to remain in service for a longer period. If each installation were to begin in 2021 to replace equipment based on its end of operational life each year, retain R-22 refrigerant for servicing remaining R-22 equipment, they would achieve complete removal of R-22 by 2040 . The initial years of the project would have the highest costs due to the amount of equipment that has reached end of operational life; costs in 2021 would be approximately $\$ 72,980,853$ (Figure 8-3). This annual cost would decrease as the project period extends to nearly 20 years, as opposed to 10 years in the first strategy.

Yearly budgetary costs were calculated from the available BUILDER dataset, i.e., $30 \%$ of the total IMCOM equipment to illustrate the yearly investment strategy. These costs were based on the available CRV within the BUILDER dataset.

Figure 8-3. Replace R-22 equipment by EOL.

Strategy 2: Replace Equipment Based on EOL

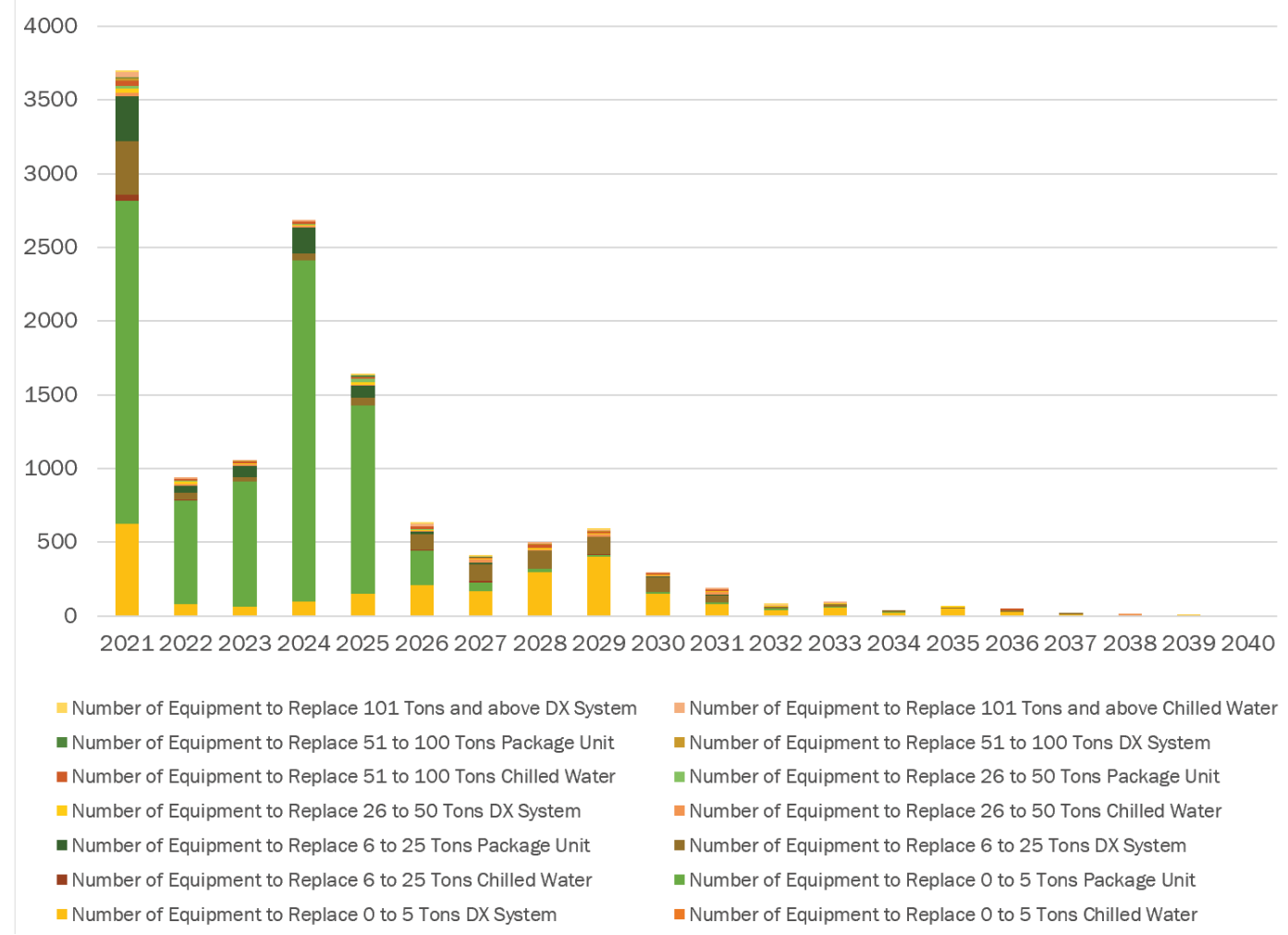


Tables 8-7 to 8-11 list the yearly expenditure if the Army moves to eliminate R-22 equipment every year based on expected EOL. These calculations only consider equipment from the available $30 \%$ of IMCOM BUILDER dataset.

Table 8-7. Cost to replace equipment by EOL (0 to 5 tons).

\begin{tabular}{|c|c|c|c|c|c|c|c|}
\hline \multirow[b]{2}{*}{ Year } & \multicolumn{2}{|c|}{$\begin{array}{c}\text { Chilled Water System } \\
\text { (20yrs) }\end{array}$} & \multicolumn{2}{|c|}{$\begin{array}{l}\text { DX System } \\
\text { (20yrs) }\end{array}$} & \multicolumn{2}{|c|}{$\begin{array}{l}\text { Packaged Unit } \\
\text { (15yrs) }\end{array}$} & \multirow{2}{*}{$\begin{array}{c}\text { Total } \\
\text { Replacement } \\
\text { Cost (\$/year) }\end{array}$} \\
\hline & $\begin{array}{c}\text { \# of } \\
\text { Equip }\end{array}$ & Cost (\$) & $\begin{array}{l}\text { \# of } \\
\text { Equip }\end{array}$ & Cost (\$) & $\begin{array}{c}\text { \# of } \\
\text { Equip }\end{array}$ & Cost (\$) & \\
\hline 2021 & 0 & - & 624 & $2,546,456.64$ & 2195 & $27,964,695.10$ & $\$ 30,511,152$ \\
\hline 2022 & 2 & $33,394.86$ & 79 & $322,387.94$ & 703 & $8,956,346.54$ & $\$ 9,312,129$ \\
\hline 2023 & 0 & - & 63 & $257,094.18$ & 848 & $10,803,672.64$ & $\$ 11,060,767$ \\
\hline 2024 & 0 & - & 99 & $404,005.14$ & 2312 & $29,455,296.16$ & $\$ 29,859,301$ \\
\hline 2025 & 0 & - & 153 & $624,371.58$ & 1272 & $16,205,508.96$ & $\$ 16,829,881$ \\
\hline 2026 & 0 & - & 206 & $840,657.16$ & 240 & $3,057,643.20$ & $\$ 3,898,300$ \\
\hline 2027 & 0 & - & 167 & $681,503.62$ & 62 & $789,891.16$ & $\$ 1,471,395$ \\
\hline 2028 & 0 & - & 295 & $1,203,853.70$ & 26 & $331,244.68$ & $\$ 1,535,098$ \\
\hline 2029 & 2 & $33,394.86$ & 403 & $1,644,586.58$ & 10 & $127,401.80$ & $\$ 1,805,383$ \\
\hline 2030 & 0 & - & 149 & $608,048.14$ & 13 & $165,622.34$ & $\$ 773,670$ \\
\hline 2031 & 0 & - & 77 & $314,226.22$ & 13 & $165,622.34$ & $\$ 479,849$ \\
\hline 2032 & 0 & - & 41 & $167,315.26$ & 11 & $140,141.98$ & $\$ 307,457$ \\
\hline 2033 & 0 & - & 56 & $228,528.16$ & 4 & $50,960.72$ & $\$ 279,489$ \\
\hline 2034 & 0 & - & 23 & $93,859.78$ & 4 & $50,960.72$ & $\$ 144,821$ \\
\hline 2035 & 0 & - & 49 & $199,962.14$ & 2 & $25,480.36$ & $\$ 225,443$ \\
\hline 2036 & 0 & - & 29 & $118,344.94$ & 0 & - & $\$ 118,345$ \\
\hline 2037 & 0 & - & 9 & $36,727.74$ & 0 & - & $\$ 36,728$ \\
\hline 2038 & 0 & - & 0 & - & 0 & - & 0 \\
\hline 2039 & 0 & - & 4 & $16,323.44$ & 0 & - & $\$ 16,323$ \\
\hline 2040 & 0 & - & 0 & - & 0 & - & 0 \\
\hline Total: & 4 & $\$ 66,790$ & 2526 & $\$ 10,308,252$ & 7715 & $\$ 98,290,489$ & $\$ 108,665,531$ \\
\hline
\end{tabular}

Table 8-8. Cost to replace equipment by EOL (6 to 25 tons).

\begin{tabular}{|c|c|c|c|c|c|c|c|}
\hline \multirow[b]{2}{*}{ Year } & \multicolumn{2}{|c|}{$\begin{array}{c}\text { Chilled Water System } \\
\text { (20yrs) }\end{array}$} & \multicolumn{2}{|c|}{$\begin{array}{l}\text { DX System } \\
\text { (20yrs) }\end{array}$} & \multicolumn{2}{|c|}{$\begin{array}{l}\text { Packaged Unit } \\
\text { (15yrs) }\end{array}$} & \multirow{2}{*}{$\begin{array}{c}\text { Total } \\
\text { Replacement } \\
\text { Cost (\$/year) }\end{array}$} \\
\hline & $\begin{array}{l}\text { \# of } \\
\text { Equip }\end{array}$ & Cost (\$) & $\begin{array}{l}\text { \# of } \\
\text { Equip }\end{array}$ & Cost (\$) & $\begin{array}{l}\text { \# of } \\
\text { Equip }\end{array}$ & Cost (\$) & \\
\hline 2021 & 39 & $3,953,447.94$ & 361 & $3,057,457.01$ & 309 & $17,086,127.19$ & $\$ 24,097,032$ \\
\hline 2022 & 5 & $506,852.30$ & 45 & $381,123.45$ & 51 & $2,820,040.41$ & $\$ 3,708,016$ \\
\hline
\end{tabular}




\begin{tabular}{|c|c|c|c|c|c|c|c|}
\hline \multirow[b]{2}{*}{ Year } & \multicolumn{2}{|c|}{$\begin{array}{c}\text { Chilled Water System } \\
\text { (20yrs) }\end{array}$} & \multicolumn{2}{|c|}{$\begin{array}{l}\text { DX System } \\
\text { (20yrs) }\end{array}$} & \multicolumn{2}{|c|}{$\begin{array}{l}\text { Packaged Unit } \\
\text { (15yrs) }\end{array}$} & \multirow{2}{*}{$\begin{array}{c}\text { Total } \\
\text { Replacement } \\
\text { Cost (\$/year) }\end{array}$} \\
\hline & $\begin{array}{l}\text { \# of } \\
\text { Equip }\end{array}$ & Cost (\$) & $\begin{array}{l}\text { \# of } \\
\text { Equip }\end{array}$ & Cost (\$) & $\begin{array}{l}\text { \# of } \\
\text { Equip }\end{array}$ & Cost (\$) & \\
\hline 2023 & 2 & $202,740.92$ & 26 & $220,204.66$ & 80 & $4,423,592.80$ & $\$ 4,846,538$ \\
\hline 2024 & 2 & $202,740.92$ & 46 & $389,592.86$ & 174 & $9,621,314.34$ & $\$ 10,213,648$ \\
\hline 2025 & 3 & $304,111.38$ & 54 & $457,348.14$ & 80 & $4,423,592.80$ & $\$ 5,185,052$ \\
\hline 2026 & 6 & $608,222.76$ & 102 & $863,879.82$ & 19 & $1,050,603.29$ & $\$ 2,522,706$ \\
\hline 2027 & 8 & $810,963.68$ & 112 & $948,573.92$ & 14 & $774,128.74$ & $\$ 2,533,666$ \\
\hline 2028 & 0 & - & 121 & $1,024,798.61$ & 0 & - & $\$ 1,024,799$ \\
\hline 2029 & 7 & $709,593.22$ & 113 & $957,043.33$ & 1 & $55,294.91$ & $\$ 1,721,931$ \\
\hline 2030 & 0 & - & 101 & $855,410.41$ & 6 & $331,769.46$ & $\$ 1,187,180$ \\
\hline 2031 & 3 & $304,111.38$ & 48 & $406,531.68$ & 2 & $110,589.82$ & $\$ 821,233$ \\
\hline 2032 & 0 & - & 11 & $93,163.51$ & 1 & $55,294.91$ & $\$ 148,458$ \\
\hline 2033 & 0 & - & 20 & $169,388.20$ & 1 & $\$ 55,294.91$ & $\$ 224,683$ \\
\hline 2034 & 0 & - & 14 & $118,571.74$ & 0 & - & $\$ 118,572$ \\
\hline 2035 & 0 & - & 7 & $59,285.87$ & 0 & - & $\$ 59,286$ \\
\hline 2036 & 0 & - & 9 & $76,224.69$ & 0 & - & $\$ 76,225$ \\
\hline 2037 & 0 & - & 4 & $33,877.64$ & 0 & - & $\$ 33,878$ \\
\hline 2038 & 0 & - & 5 & $42,347.05$ & 0 & $\$-$ & $\$ 42,347$ \\
\hline 2039 & 0 & - & 0 & - & 0 & - & 0 \\
\hline Total: & 75 & $\$ 7,602,785$ & 1199 & $\$ 10,154,823$ & 738 & $\$ 40,807,644$ & $\$ 58,565,251$ \\
\hline
\end{tabular}

Table 8-9. Cost to replace equipment by EOL (26 to 50 tons).

\begin{tabular}{|c|c|c|c|c|c|c|c|}
\hline \multirow[b]{2}{*}{ Year } & \multicolumn{2}{|c|}{$\begin{array}{c}\text { Chilled Water System } \\
\text { (20yrs) }\end{array}$} & \multicolumn{2}{|c|}{$\begin{array}{c}\text { DX System } \\
\text { (20yrs) }\end{array}$} & \multicolumn{2}{|c|}{$\begin{array}{c}\text { Packaged Unit } \\
\text { (20yrs) }\end{array}$} & \multirow{2}{*}{$\begin{array}{c}\text { Total } \\
\text { Replacement } \\
\text { Cost (\$/year) }\end{array}$} \\
\hline & $\begin{array}{l}\text { \# of } \\
\text { Equip }\end{array}$ & Cost (\$) & $\begin{array}{l}\text { \# of } \\
\text { Equip }\end{array}$ & Cost (\$) & $\begin{array}{l}\text { \# of } \\
\text { Equip }\end{array}$ & Cost (\$) & \\
\hline 2021 & 24 & $2,432,891.04$ & 25 & $591,975.00$ & 4 & $451,372.00$ & $\$ 3,476,238$ \\
\hline 2022 & 11 & $1,115,075.06$ & 15 & $355,185.00$ & 4 & $451,372.00$ & $\$ 1,921,632$ \\
\hline 2023 & 10 & $1,013,704.60$ & 5 & $118,395.00$ & 1 & $112,843.00$ & $\$ 1,244,943$ \\
\hline 2024 & 14 & $1,419,186.44$ & 6 & $142,074.00$ & 4 & $451,372.00$ & $\$ 2,012,632$ \\
\hline 2025 & 9 & $912,334.14$ & 14 & $331,506.00$ & 3 & $338,529.00$ & $\$ 1,582,369$ \\
\hline 2026 & 7 & $709,593.22$ & 4 & $94,716.00$ & 4 & $451,372.00$ & $\$ 1,255,681$ \\
\hline 2027 & 22 & $2,230,150.12$ & 5 & $118,395.00$ & 7 & $789,901.00$ & $\$ 3,138,446$ \\
\hline 2028 & 5 & $506,852.30$ & 16 & $378,864.00$ & 2 & $225,686.00$ & $\$ 1,111,402$ \\
\hline 2029 & 19 & $1,926,038.74$ & 6 & $142,074.00$ & 6 & $677,058.00$ & $\$ 2,745,171$ \\
\hline 2030 & 5 & $506,852.30$ & 6 & $142,074.00$ & 26 & $2,933,918.00$ & $\$ 3,582,844$ \\
\hline 2031 & 17 & $1,723,297.82$ & 8 & $189,432.00$ & 5 & $564,215.00$ & $\$ 2,476,945$ \\
\hline
\end{tabular}




\begin{tabular}{|c|c|c|c|c|c|c|c|}
\hline \multirow[b]{2}{*}{ Year } & \multicolumn{2}{|c|}{$\begin{array}{c}\text { Chilled Water System } \\
\text { (20yrs) }\end{array}$} & \multicolumn{2}{|c|}{$\begin{array}{l}\text { DX System } \\
\text { (20yrs) }\end{array}$} & \multicolumn{2}{|c|}{$\begin{array}{l}\text { Packaged Unit } \\
\text { (20yrs) }\end{array}$} & \multirow{2}{*}{$\begin{array}{c}\text { Total } \\
\text { Replacement } \\
\text { Cost (\$/year) }\end{array}$} \\
\hline & $\begin{array}{l}\text { \# of } \\
\text { Equip }\end{array}$ & Cost (\$) & $\begin{array}{l}\text { \# of } \\
\text { Equip }\end{array}$ & Cost (\$) & $\begin{array}{l}\text { \# of } \\
\text { Equip }\end{array}$ & Cost (\$) & \\
\hline 2032 & 0 & - & 2 & $47,358.00$ & 0 & - & $\$ 47,358$ \\
\hline 2033 & 0 & - & 3 & $71,037.00$ & 0 & - & $\$ 71,037$ \\
\hline 2034 & 0 & - & 0 & - & 0 & - & 0 \\
\hline 2035 & 0 & - & 2 & $47,358.00$ & 0 & - & $\$ 47,358$ \\
\hline 2036 & 0 & - & 0 & - & 0 & - & 0 \\
\hline 2037 & 0 & - & 0 & - & 0 & - & 0 \\
\hline 2038 & 1 & $101,370.46$ & 0 & - & 0 & - & $\$ 101,370$ \\
\hline 2039 & 0 & - & 0 & - & 0 & - & 0 \\
\hline 2040 & 0 & - & 0 & - & 0 & - & 0 \\
\hline Total: & 144 & $\$ 14,597,346$ & 117 & $\$ 2,770,443$ & 66 & $\$ 7,447,638$ & $\$ 24,815,427$ \\
\hline
\end{tabular}

Table 8-10. Cost to replace equipment by EOL (51 to 100 tons).

\begin{tabular}{|c|c|c|c|c|c|c|c|}
\hline \multirow[b]{2}{*}{ Year } & \multicolumn{2}{|c|}{$\begin{array}{c}\text { Chilled Water System } \\
\text { (20yrs) }\end{array}$} & \multicolumn{2}{|c|}{$\begin{array}{l}\text { DX System } \\
\text { (20yrs) }\end{array}$} & \multicolumn{2}{|c|}{$\begin{array}{c}\text { Packaged Unit } \\
\text { (15yrs) }\end{array}$} & \multirow{2}{*}{$\begin{array}{c}\text { Total } \\
\text { Replacement } \\
\text { Cost (\$/year) }\end{array}$} \\
\hline & $\begin{array}{c}\text { \# of } \\
\text { Equip }\end{array}$ & Cost (\$) & $\begin{array}{c}\text { \# of } \\
\text { Equip }\end{array}$ & Cost (\$) & $\begin{array}{c}\text { \# of } \\
\text { Equip }\end{array}$ & Cost (\$) & \\
\hline 2021 & 32 & $3,946,893.76$ & 19 & $560,025.57$ & 4 & $\$ 849,744.00$ & $\$ 5,356,663$ \\
\hline 2022 & 14 & $1,726,766.02$ & 0 & - & 0 & - & $\$ 1,726,766$ \\
\hline 2023 & 12 & $1,480,085.16$ & 2 & $58,950.06$ & 0 & - & $\$ 1,539,035$ \\
\hline 2024 & 18 & $2,220,127.74$ & 0 & - & 2 & $424,872.00$ & $\$ 2,645,000$ \\
\hline 2025 & 10 & $1,233,404.30$ & 2 & $58,950.06$ & 10 & $2,124,360.00$ & $\$ 3,416,714$ \\
\hline 2026 & 16 & $1,973,446.88$ & 2 & $58,950.06$ & 2 & $424,872.00$ & $\$ 2,457,269$ \\
\hline 2027 & 9 & $1,110,063.87$ & 0 & - & 2 & $424,872.00$ & $\$ 1,534,936$ \\
\hline 2028 & 23 & 2,836,829.89 & 2 & $58,950.06$ & 0 & - & $\$ 2,895,780$ \\
\hline 2029 & 12 & $1,480,085.16$ & 6 & $176,850.18$ & 0 & - & $\$ 1,656,935$ \\
\hline 2030 & 8 & $986,723.44$ & 0 & - & 0 & - & $\$ 986,723$ \\
\hline 2031 & 10 & $1,233,404.30$ & 0 & - & 0 & - & $\$ 1,233,404$ \\
\hline 2032 & 0 & - & 0 & - & 0 & - & - \\
\hline 2033 & 0 & - & 2 & $58,950.06$ & 0 & - & $\$ 58,950$ \\
\hline 2034 & 0 & - & 0 & - & 0 & - & 0 \\
\hline 2035 & 0 & - & 0 & - & 0 & - & 0 \\
\hline 2036 & 2 & $246,680.86$ & 0 & - & 0 & - & $\$ 246,681$ \\
\hline 2037 & 0 & - & 0 & - & 0 & - & 0 \\
\hline 2038 & 0 & - & 0 & - & 0 & - & 0 \\
\hline 2039 & 0 & - & 0 & - & 0 & - & 0 \\
\hline
\end{tabular}




\begin{tabular}{|c|r|r|r|r|r|r|r|}
\hline 2040 & 0 & - & 0 & - & 0 & - & 0 \\
\hline Total: & 166 & $\$ 20,474,511$ & 35 & $\$ 1,031,626$ & 20 & $\$ 4,248,720$ & $\$ 25,754,857$ \\
\hline
\end{tabular}

Table 8-11. Cost to replace equipment by EOL (101 tons and above).

\begin{tabular}{|c|c|c|c|c|c|}
\hline \multirow[b]{2}{*}{ Year } & \multicolumn{2}{|c|}{$\begin{array}{c}\text { Chilled Water System } \\
\text { (20yrs) }\end{array}$} & \multicolumn{2}{|c|}{$\begin{array}{l}\text { DX System } \\
\text { (20yrs) }\end{array}$} & \multirow{2}{*}{$\begin{array}{l}\text { Total } \\
\text { Replacement } \\
\text { Cost }(\$ / \text { year) }\end{array}$} \\
\hline & $\begin{array}{l}\text { \# of } \\
\text { Equip }\end{array}$ & Cost (\$) & $\begin{array}{l}\text { \# of } \\
\text { Equip }\end{array}$ & Cost (\$) & \\
\hline 2021 & 37 & $9,436,774.89$ & 1 & $102,992.81$ & $\$ 9,539,768$ \\
\hline 2022 & 4 & 1,020,191.88 & 0 & - & $\$ 1,020,192$ \\
\hline 2023 & 3 & $765,143.91$ & 0 & - & $\$ 765,144$ \\
\hline 2024 & 5 & $1,275,239.85$ & 0 & - & $\$ 1,275,240$ \\
\hline 2025 & 1 & $255,047.97$ & 2 & $205,985.62$ & $\$ 461,034$ \\
\hline 2026 & 16 & $4,080,767.52$ & 2 & $205,985.62$ & $\$ 4,286,753$ \\
\hline 2027 & 2 & $510,095.94$ & 2 & $205,985.62$ & $\$ 716,082$ \\
\hline 2028 & 15 & $3,825,719.55$ & 0 & - & $\$ 3,825,720$ \\
\hline 2029 & 3 & $765,143.91$ & 2 & $205,985.62$ & $\$ 971,130$ \\
\hline 2030 & 4 & $1,020,191.88$ & 0 & - & $\$ 1,020,192$ \\
\hline 2031 & 3 & $765,143.91$ & 0 & - & $\$ 765,144$ \\
\hline 2032 & 6 & $1,530,287.82$ & 2 & $205,985.62$ & $\$ 1,736,273$ \\
\hline 2033 & 2 & $510,095.94$ & 0 & - & $\$ 510,096$ \\
\hline 2034 & 0 & - & 0 & - & 0 \\
\hline 2035 & 0 & - & 0 & - & 0 \\
\hline 2036 & 0 & - & 0 & - & 0 \\
\hline 2037 & 0 & - & 0 & - & 0 \\
\hline 2038 & 0 & - & 0 & - & 0 \\
\hline 2039 & 0 & - & 0 & - & 0 \\
\hline 2040 & 0 & - & 0 & - & 0 \\
\hline Total: & 101 & $\$ 25,759,845$ & 11 & $\$ 1,132,921$ & $\$ 26,892,766$ \\
\hline \multicolumn{6}{|c|}{$\begin{array}{l}\text { *Large equipment needs special attention and further investigation to understand the } \\
\text { complexity of the replacement procedure. Though we have provided budgetary costs for the } \\
\text { replacement, the actual process can be complex and therefore will require detailed } \\
\text { engineering analysis for decision making. }\end{array}$} \\
\hline
\end{tabular}




\section{Conclusion}

\subsection{Summary}

This project conducted a survey to determine the current R-22 usage and types of R-22 AC\&R equipment that are in use across IMCOM installations. This study describes several methods to remove or retrofit R-22 from typical AC\&R equipment to meet the stated goal of eliminating the use of R-22 for comfort cooling on IMCOM installations. These methods were further analyzed to determine the most viable methods and develop strategies to implement them.

The scope of this project included the review of BUILDER SMS data for IMCOM installations, which included data on 13,000 pieces of comfort cooling equipment for 31 installations, along with a survey of R-22 supply information and available refrigerant alternatives. Mission critical tactical cooling that uses R-22 refrigerant was not within the scope of this project.

The study determined that approximately 43,00o pieces of AC\&R equipment are in use across IMCOM, as extrapolated from the available BUILDER data. This corresponds to an approximate cooling capacity of $3,369,247$ tons and refrigerant demand between 13,476,987 lbs. (at 4 lbs. per ton) to 20,215,480 lbs. (at $6 \mathrm{lbs}$. per ton). With this information, three methods to eliminate R-22 from equipment and two implementation strategies were outlined, which were determined by analyzing the provided BUILDER dataset. The most economical method for the orderly elimination of R-22 from IMCOM facilities is to replace condensing equipment as it reaches its expected end of operational life. However, two additional methods were discussed to eliminate R-22 from equipment before its end of operational life. The other methods include the retrofit of the existing system with new refrigerant, or compressor replacement. Both methods are shown to be less life cycle cost effective when compared to replacing equipment after end of operational life. Using either of the latter two methods may also result in additional system issues and can also lead to capacity losses.

The resulting elimination strategies call for the replacement of R-22 equipment based on age and the systematic increase of R-22 reserves by capturing R-22 from these legacy systems. The two strategies were developed to eliminate R-22 equipment by 2030 to meet the Montreal Protocol or the 
systematic removal of equipment as it reaches end of operational life to the year 2040. Either of these strategies could be deployed to eliminate R-22 as determined by IMCOM and their desired path forward.

The findings in this report were based on the available 30\% IMCOM data and predicted averages for the remaining facilities. These data were used to perform an economic analysis and provide recommendations for the R22 phase-out strategy. As a majority of the IMCOM data were not available at the time of this study, the data were extrapolated to determine approximate values for calculation purposes. Therefore, it is not advisable to use the full predicted values for acquiring grants or drafting budgets. It is beneficial to use the given data to evaluate the phase-out strategy, potential equipment considerations, and to forecast demand. For any R-22-related project, it is necessary to perform an individualized analysis for each IMCOM installation to further evaluate precise demand, equipment, and costing to develop an accurate project estimate.

\subsection{Path forward - Future technologies}

Chapters 2 and 3 of this report briefly discussed the evolving refrigerant and regulatory environments that are causing uncertainties regarding future potential R-22 alternatives. Chapter 6 outlined several HFC refrigerants that are acceptable for use as replacements to R-22, e.g., R-407C, R417A, R-422B, R-422D, R-438A, and R-507A, but that come with higher GWP than R-22. As the world shifts toward stricter regulation of refrigerants with GWP, there is a need for a more permanent solution that is environmentally safe and relatively free of further regulation.

A reviewing of literature concerning refrigerant alternatives indicates that carbon dioxide $\left(\mathrm{CO}_{2}\right)$ may have a potential as an R-22 alternative. $\mathrm{CO}_{2}$, also designated as R-744, has emerged in the market as a new candidate refrigerant. $\mathrm{CO}_{2}$ is an environmentally friendly compound with good heat transfer properties with high latent heat of vaporization. $\mathrm{CO}_{2}$ has an ODP of zero and GWP of 1 making it a complete environmentally safe option when compared to R-22 or other HFC compounds.

$\mathrm{CO}_{2}$ systems and $\mathrm{HFC}$ systems operate at different operational conditions. Generally, HFC and HCFC refrigerant systems operate below their respective critical pressures. In contrast, $\mathrm{CO}_{2}$ refrigerant systems operate both below and above their critical temperature $\left(88^{\circ} \mathrm{F}\right)$; hence they are called 
"transcritical" systems. This unique property makes $\mathrm{CO}_{2}$ advantageous when compared to HFC refrigerants.

Some of the advantages of the R-744 system include:

- Cost of an HFC refrigerant is approximately $\$ 6-\$ 8$ per pound as of 2020. However, R744 costs less than a dollar per pound.

- R-744 is environmentally safer than HFC refrigerants with an ODP of o and a GWP of 1.

- R-744 is a "future proof" compound. As regulations continually change based on the evaluation of existing synthetic refrigerants and environmental concerns, $\mathrm{R}-744$ will remain a viable option.

R-744 systems have been under development and testing for many years but have been slow to be adopted in North America. Although the U.S Army began investigating this technology in the 1990s for possible use in U.S. Army equipment, such as MVAC and ECUs, the technology has not been implemented (U.S Army 2005). Although HFC refrigerants are a common choice for R-22 retrofit options, R-744 remains a good candidate for further investigation considering its excellent environmental performance and low cost. 


\section{References}

\section{Cited Works}

ASHRAE. 2018. ASHRAE Position Document on Refrigerants and their Responsible Use. Atlanta, GA: ASHRAE.

2019. "Table 4 Comparison of Service Life Estimates." ASHRAE Handbook:

Heating, Ventilation, and Air-Conditioning Applications. Atlanta, GA: ASHRAE.

ANSI/ASHRAE (American National Standards Institute/ASHRAE). 2019. Safety Standard for Refrigeration Systems and Designation and Safety Classification of Refrigerants. Standard 34. Atlanta, GA: ASHRAE.

ERDC-CERL (Engineer Research and Development Center, Construction Engineering Research Laboratory). 2019. BUILDER Custom Reports-Specific to U.S. Air Force. https://buildersummit.com/wp-content/uploads/2018/11/USAF-BUILDER-CustomReports.pdf.

Grussing, Michael N. 2012. Facility Degradation and Prediction Models for Sustainment, Restoration and Modernization (SRM) Planning. ERDC/CERL TR-12-13. Champaign, IL: Engineer Research and Development Center, Construction Engineering Research Laboratory (ERDC-CERL), https://apps.dtic.mil/dtic/tr/fulltext/u2/a570002.pdf. Pp 16-18

RS Means, Building Construction Estimation Guide 25th. 2010. Heating, Ventilation and Air-Conditioning Data. Section 608 of the Clean Air Act. 2015. EPA 430-F-18001. https://www.epa.gov/sites/production/files/201508/documents/section_608_of_the_clean_air_act.pdf. pp 760-781.

Spletzer, Stephen. 2013. $R$-22 Alternatives. Atlanta, GA: ASHRAE. https://mnashrae.org/downloads/2013_Presentations/r_22_alternatives_ashrae_version.pdf.

DoA (U.S. Department of the Army). 2008. $R$-22 Refrigerant Use on Army Installations, https://www.denix.osd.mil/army-ods/home/ods-policy/acsim-memo/ARMY\%20R-22\%20TURNIN\%20POLICY\%20(ACSIM\%20Memo\%2006-12-2008).pdf.

. 2018a. R-22 Refrigerant Use on Army Installations. https://www.denix.osd.mil/armyods/home/ods-policy/dasa-apl/ARMY\%200DS\%20POLICY\%20(DASA(APL)\%20Memo\%200517-2018).pdf.

2018b. U.S. Management of the U.S. Army Ozone-Depleting Substances (ODS) Reserve. https://www.denix.osd.mil/army-ods/home/odsreserve/plan/ARMY\%200DS\%20RESERVE\%20MANAGEMENT\%20PLAN\%2010-4-2018.pdf.

2019. Army R-22 Strategy. Environmental Support Office. https://www.denix.osd.mil/army-ods/home/ods-strategy/army-r-22-strategy-july-2019pdf/ARMY\%20R-22\%20STRATEGY\%20July\%202019.pdf.

2020. Executive Summary: Army Ozone Depleting Substances (ODS) Elimination Program. https://www.denix.osd.mil/army-ods/home/executivesummary/summary/EXECUTIVE\%20SUMMARY\%200DS\%202020.pdf. 
DoE (U.S. Department of Energy). 2015. History of Air-conditioning. https://www.energy.gov/articles/history-air-conditioning.

U.S. Department of State. https://www.state.gov/key-topics-office-of-environmental-quality-andtransboundary-issues/the-montreal-protocol-on-substances-that-deplete-the-ozone-layer/.

(USEPA) U.S. Environmental Protection Agency. 2020a. Ozone Layer Protection. Website. https://www.epa.gov/ozone-layer-protection. 2020b. Phaseout of Class II Ozone-Depleting Substances. Website. https://www.epa.gov/ods-phaseout/phaseout-class-ii-ozone-depleting-substances. 2015. Clean Air Act (CAA) of 1990. Title VI. Section 612. "Evaluation of Submissions under Clean Air Act."

\section{Uncited Works}

Abdelaziz, O., S. Shrestha, B. Shen, R. Linkous, W. Goetzler, M. Guernsey, and Y. Bargach. 2016. Alternative Refrigerant Evaluation for High-AmbientTemperature Environments. ORNL/TM-2016/513. Oak Ridge, TN: Oak Ridge National Laboratory.

Booten, Charles W., Scott R. Nicholson, Margaret K. Mann, and Omar Abdelaziz. 2020. Refrigerants: Market Trends and Supply Chain Assessment. NREL/TP-550070207. Golden, CO: National Renewable Energy Lab.

McGowan, Mary Kate. 2018. Adopting Alternative Refrigerants: Conversion Challenges and Applications. Atlanta, GA: ASHRAE.

Polzot, Alessio, Paola D'Agaro, and Giovanni Cortella. 2017. "Energy Analysis of a Transcritical $\mathrm{CO}_{2}$ Supermarket Refrigeration System with Heat Recovery.” Energy Procedia 111(2017):648-657.

Schultz, Ken. 2014. "System Drop-In Test of R-410A, R-22 and R-134a Alternative Refrigerants in Chillers." Air-conditioning, Heating and Refrigeration Institute (AHRI) Conference. http://www.ahrinet.org/App_Content/ahri/files/RESEARCH/AREP2014Conference/CHILLER02_Ingersoll_Rand-Trane.pdf.

Trane. 2018. What You Need to Know about R-22 Retrofit. White Paper. https://www.agas.com/media/6233/r22_phase_out_alternatives_061318.pdf.

DoA (U.S. Department of the Army). 2005. $\mathrm{CO}_{2}$ Cooling Development Team. Communications-Electronics RD\&E. Environmental Excellence in Weapons Systems Acquisition.

DoE (U.S. Department of Energy). 2020. EPA Significant New Alternatives Program. https://www.epa.gov/snap.

United National Environment Program. 2019. Update on New Refrigerant Designations and Safety Classifications. https://www.unenvironment.org/ozonaction/resources/factsheet/update-new-refrigerantsdesignations-and-safety-classifications. 
Wang, X., and K. Amrane. 2014. "AHRI Low-GWP Alternative Refrigerants Evaluation Program (Low-GWP AREP) - Summary of Phase I Testing Results.” International Refrigeration and Air-conditioning Conference. . 2016. AHRI Low Global Warming Potential Alternative Refrigerants Evaluation Program (Low-GWP AREP) Summary of Phase II Testing Results. 


\section{Acronyms and Abbreviations}

\begin{tabular}{|c|c|}
\hline Abbreviation & Term \\
\hline$A C \& R$ & Air-Conditioning and Refrigeration \\
\hline ASHRAE & American Society of Heating, Refrigerating and Air-Conditioning Engineers \\
\hline CAA & Clean Air Act \\
\hline CERL & Construction Engineering Research Laboratory \\
\hline CFC & Chlorofluorocarbons \\
\hline $\mathrm{Cl}$ & Condition Index \\
\hline CRV & Component Replacement Value \\
\hline DLA & Defense Logistics Agency \\
\hline DoD & Department of Defense \\
\hline DX & Direct Expansion \\
\hline ECU & Environmental Control Units \\
\hline EOL & Equipment Operational Life \\
\hline ERDC & Engineer Research and Development Center \\
\hline ESO & Environmental Support Office \\
\hline GSA & General Service Administration \\
\hline GWP & Global Warming Potential \\
\hline HCFC & Hydrochlorofluorocarbons \\
\hline HFC & Hydrofluorocarbons \\
\hline HVAC & Heating, Ventilating, and Air-Conditioning \\
\hline IMCOM & U.S. Army Installation Management Command \\
\hline LCCA & Life-Cycle Cost Analysis \\
\hline MVAC & Motor Vehicle Air-Conditioning \\
\hline NPV & Net Present Value \\
\hline ODP & Ozone-Depleting Potential \\
\hline ODS & Ozone-Depleting Substance \\
\hline OEM & Original Equipment Manufacturer \\
\hline POE & Polyolester \\
\hline RSL & Remaining Service Life \\
\hline SEER & Seasonal Efficiency Rating \\
\hline SNAP & Significant New Alternatives Policy \\
\hline TXV & Thermal Expansion Valve \\
\hline USACE & U.S. Army Corps of Engineers \\
\hline USEPA & U.S. Environmental Protection Agency \\
\hline UV & Ultraviolet \\
\hline
\end{tabular}




\section{Unit Conversion Factors}

\begin{tabular}{|l|c|l|}
\hline Multiply & By & To Obtain \\
\hline British thermal units (International Table) & $1,055.056$ & joules \\
\hline degrees Fahrenheit & $(\mathrm{F}-32) / 1.8$ & degrees Celsius \\
\hline square feet & 0.09290304 & square meters \\
\hline tons (force) & $8,896.443$ & newtons \\
\hline tons (force) per square foot & 95.76052 & kilopascals \\
\hline tons (2,000 pounds, mass) & 907.1847 & kilograms \\
\hline
\end{tabular}




\section{Appendix A: IMCOM BUILDER Data}

\section{A.1 IMCOM BUILDER implementation status}

Table A-1 lists the BUILDER SMS implementation status at IMCOM installations. BUILDER implementation at IMCOM installations is still in progress, although delayed due to restrictions and delays arising from the pandemic. The BUILDER SMS team was able to provide data for the installations that were complete or mostly in progress as of April 2020. Additional data were not provided or not available for other in progress implementations.

Table A-1. BUILDER implementation status as of April 2020.

\begin{tabular}{|c|c|}
\hline Installation & Status as of April 2020 \\
\hline Aberdeen Proving Ground & $38 \%$ \\
\hline Camp Casey & Planned FY20 \\
\hline Camp Henry & Planned FY20 \\
\hline Camp Humphreys & Planned FY20 \\
\hline Camp Red Cloud & Planned FY20 \\
\hline Camp Zama & Planned FY20 \\
\hline Carlisle Barracks & Complete \\
\hline Detroit Arsenal & In Progress \\
\hline Dugway Proving Ground & Complete \\
\hline Fort A P Hill & Complete \\
\hline Fort Belvoir & Complete \\
\hline Fort Benning & $42 \%$ \\
\hline Fort Bliss & $24 \%$ \\
\hline Fort Bragg & $47 \%$ \\
\hline Fort Campbell & $52 \%$ \\
\hline Fort Carson & Complete \\
\hline Fort Detrick & Complete \\
\hline Fort Drum & Planned FY20 \\
\hline Fort George G Meade & Complete \\
\hline Fort Gordon & Complete \\
\hline Fort Greely & Planned FY20 \\
\hline Fort Hamilton & Complete \\
\hline Fort Huachuca & Planned FY20 \\
\hline Fort Hood & Complete \\
\hline Fort Irwin National Training Center & Planned FY20 \\
\hline Fort Jackson & Planned FY20 \\
\hline Fort Knox & $95 \%$ \\
\hline Fort Leavenworth & Planned FY20 \\
\hline Fort Lee & Planned FY20 \\
\hline Fort Leonard Wood & Complete \\
\hline Fort Polk & $61 \%$ \\
\hline Fort Riley & $53 \%$ \\
\hline Fort Rucker & $96 \%$ \\
\hline
\end{tabular}




\begin{tabular}{|c|c|}
\hline Installation & Status as of April 2020 \\
\hline Fort Sill & Planned FY20 \\
\hline Fort Shafter & Planned FY20 \\
\hline Fort Stewart & $61 \%$ \\
\hline Fort Wainwright & Planned FY20 \\
\hline Joint Base Lewis-McChord & Complete \\
\hline Joint Base Myer-Henderson Hall & Complete \\
\hline Natick Soldier Systems Center & Complete \\
\hline Picatinny Arsenal & $62 \%$ \\
\hline Presidio of Monterey & Planned FY20 \\
\hline Redstone Arsenal & Complete \\
\hline Rock Island Arsenal & Planned FY20 \\
\hline Schofield Barracks & Planned FY20 \\
\hline Soto Cano & Complete \\
\hline U.S. Army Adelphi Laboratory Center & In Progress \\
\hline U.S. Army Garrison Ansbach & Planned FY20 \\
\hline U.S. Army Garrison Bavaria & Planned FY20 \\
\hline U.S. Army Garrison Benelux & Planned FY20 \\
\hline U.S. Army Garrison Italy & Planned FY20 \\
\hline U.S. Army Garrison Kwajalein Atoll & Planned FY20 \\
\hline U.S. Army Garrison Miami & Complete \\
\hline U.S. Army Garrison Rhineland-Pfalz & Planned FY20 \\
\hline U.S. Army Garrison Stuttgart & Planned FY20 \\
\hline U.S. Army Garrison Wiesbaden & Planned FY20 \\
\hline U.S. Army Kwajalein Atoll & Planned FY20 \\
\hline West Point Military Reservation & Complete \\
\hline White Sands Missile Range & Planned FY20 \\
\hline Yongsan Garrison & Planned FY20 \\
\hline Yuma Proving Ground & Complete \\
\hline
\end{tabular}

Table A-2 was used for calculation purposes to extrapolate the available $30 \%$ of IMCOM installations out to $100 \%$, as based on square footage.

Table A-2. BUILDER implementation status based on building footage.

\begin{tabular}{|l|l|}
\hline Command & IMCOM \\
\hline Percent Complete by Square Footage & $29.9 \%$ \\
\hline Completed Square Footage & $218,570,324.8$ \\
\hline Total Square Footage & $734,966,513$ \\
\hline
\end{tabular}

\section{A.2 BUILDER equipment summary based on capacities}

Table A-3. R-22 Equipment by IMCOM installation, based on capacity.

\begin{tabular}{|l|c|c|l|l|l|}
\hline \multirow{2}{*}{$\begin{array}{l}\text { IMCOM Installation } \\
\text { (BUILDER Implementation }\end{array}$} & \multicolumn{5}{|c|}{ Capacity } \\
\cline { 2 - 6 } $\begin{array}{l}\text { Status, April 2020) } \\
\text { 0 to 5 Tons }\end{array}$ & 6 to 25 Tons & $\begin{array}{l}\text { 26 to } 100 \\
\text { Tons }\end{array}$ & $\begin{array}{l}\text { Above 101 } \\
\text { Tons }\end{array}$ & Total \\
\hline $\begin{array}{l}\text { Aberdeen Proving Ground (38\% } \\
\text { Complete) }\end{array}$ & 166 & 103 & 26 & 10 & 305 \\
\hline
\end{tabular}




\begin{tabular}{|c|c|c|c|c|c|}
\hline \multirow{2}{*}{$\begin{array}{l}\text { IMCOM Installation } \\
\text { (BUILDER Implementation } \\
\text { Status, April 2020) }\end{array}$} & \multicolumn{5}{|c|}{ Capacity } \\
\hline & 0 to 5 Tons & 6 to 25 Tons & $\begin{array}{l}26 \text { to } 100 \\
\text { Tons }\end{array}$ & $\begin{array}{l}\text { Above } 101 \\
\text { Tons }\end{array}$ & Total \\
\hline Carlisle Barracks (Complete) & 67 & 47 & & 1 & 115 \\
\hline Dugway Proving Ground (Complete) & 168 & 34 & 22 & 2 & 226 \\
\hline Fort A P Hill (Complete) & 49 & 103 & & & 152 \\
\hline Fort Belvoir (Complete) & 209 & 90 & 37 & 6 & 342 \\
\hline Fort Benning ( $42 \%$ Complete) & 148 & 94 & 40 & 10 & 292 \\
\hline Fort Bliss (24\% Complete) & 128 & 54 & 5 & 4 & 191 \\
\hline Fort Bragg ( $47 \%$ Complete) & 281 & 88 & 39 & 11 & 419 \\
\hline Fort Campbell (52\% Complete) & 255 & 94 & 24 & 17 & 390 \\
\hline Fort Carson (Complete) & 83 & 28 & 22 & 10 & 143 \\
\hline Fort Detrick (Complete) & 181 & 81 & 17 & & 279 \\
\hline Fort George G Meade (Complete) & 167 & 26 & 30 & 12 & 235 \\
\hline Fort Gordon (Complete) & 150 & 73 & 15 & & 238 \\
\hline Fort Hamilton (Complete) & 2 & 6 & & & 8 \\
\hline Fort Hood (Complete) & 409 & 171 & 19 & 8 & 607 \\
\hline Fort Knox (95\% Complete) & 6252 & 228 & 38 & 2 & 6520 \\
\hline Fort Leonard Wood (Complete) & 263 & 78 & 23 & 6 & 370 \\
\hline Fort Polk (61\% Complete) & 107 & 116 & 4 & 1 & 228 \\
\hline Fort Riley (53\% Complete) & 325 & 44 & 66 & & 435 \\
\hline Fort Rucker (96\% Complete) & 243 & 130 & 40 & 2 & 415 \\
\hline Fort Stewart (61\% Complete) & 131 & 42 & 10 & & 183 \\
\hline $\begin{array}{l}\text { Joint Base Lewis-McChord } \\
\text { (Complete) }\end{array}$ & 80 & 28 & 8 & & 116 \\
\hline $\begin{array}{l}\text { Joint Base Myer-Henderson Hall } \\
\text { (Complete) }\end{array}$ & 175 & 109 & 21 & 8 & 313 \\
\hline Natick Soldier Systems Center & 32 & 14 & 2 & & 48 \\
\hline Picatinny Arsenal (62\% Complete) & 77 & 57 & 19 & 4 & 157 \\
\hline Redstone Arsenal (Complete) & 171 & 110 & 19 & & 300 \\
\hline U.S. Army Adelphi Laboratory Center & 40 & 8 & 2 & & 50 \\
\hline USAG Kwajalein Atoll & 1 & 6 & & & 7 \\
\hline $\begin{array}{l}\text { USMA West Point Military } \\
\text { Reservation (Complete) }\end{array}$ & 95 & 75 & 6 & & 176 \\
\hline Yuma Proving Ground (Complete) & 12 & 2 & & & 14 \\
\hline Total R-22 Equipment: & 10467 & 2139 & 554 & 114 & 13274 \\
\hline
\end{tabular}




\section{Appendix B: Alternative Refrigerants and Retrofit Considerations}

\section{B.1 Additional alternative refrigerants in the market}

Table B-1. List of commercially available R-22 alternative refrigerants.

\begin{tabular}{|c|c|c|c|c|c|c|c|c|}
\hline Refrigerant & $\begin{array}{l}\text { Commercial } \\
\text { Market Name }\end{array}$ & GWP & ODP & $\begin{array}{c}\text { Oil } \\
\text { (lubricant) }\end{array}$ & $\begin{array}{c}\text { Relative } \\
\text { Capacity } \\
\text { (Baseline =R22) }\end{array}$ & $\begin{array}{c}\text { Critical } \\
\text { Pressure } \\
{[\mathrm{MPa}]}\end{array}$ & $\begin{array}{c}\text { Critical } \\
\text { Temperature } \\
\left({ }^{\circ} \mathrm{F}\right)\end{array}$ & Flammability \\
\hline$R-404 \mathrm{~A}$ & Klea $\circledast 404 \mathrm{C}$ & 3922 & 0 & POE & $95 \%$ & 3.7 & 161.68 & Low \\
\hline$R-407 \mathrm{~A}$ & R-407A & 2107 & 0 & POE & $100 \%$ & 4.6 & 187.5 & Low \\
\hline R410A & Forane $₫ 410 A$ & 4300 & 0 & POE & - & 4.9 & 163.04 & Low \\
\hline $\mathrm{R}-417 \mathrm{~A}$ & ISCEON $\circledast$ MO59 & 2346 & 0 & POE & $85 \%$ & 4.0 & 188.7 & Low \\
\hline$R-421 A$ & Choice R421A & 2385 & 0 & POE & $85 \%$ & 3.9 & 181 & Low \\
\hline$R-422 B$ & ICOR XAC1 & 2290 & 0 & POE & $85-90 \%$ & 3.9 & 181.8 & Low \\
\hline$R-422 D$ & ISCEON MO29 & 2473 & 0 & POE & $80 \%$ & 3.9 & 175.2 & Low \\
\hline$R-424 A$ & RS-44b & 1636 & 0 & POE & $80 \%$ & 4.0 & 191.8 & Low \\
\hline$R-427 \mathrm{~A}$ & Forane ${ }^{\circledR}$ & 2024 & 0 & POE & $95 \%$ & 4.4 & 188.2 & Low \\
\hline$R-438 A$ & ISCEON® MO99 & 2265 & 0 & POE & $88 \%$ & 4.2 & 182.7 & Low \\
\hline$R-507 C$ & & 3600 & 0 & POE & - & 3.79 & 159.6 & Low \\
\hline
\end{tabular}

\section{B.2 Compressors - An overview}

R-22 or "Freon" has been extensively used as a refrigerant for the past several decades. R-22 resides inside a vapor-compression cycle that works to change the physical state of the refrigerant (R-22) to regulate temperature. The cycle works to change the refrigerant from a liquid to a gas in the evaporator by transferring heat from the building, which in turn cools the building. The refrigerant gas is then circulated through the HVAC system to the compressor. The compressor then compresses the refrigerant, heating it up into a high-pressure gas. This high-pressure, high temperature gas is sent to the condenser where it is changed into a liquid to be sent back to the evaporator. Therefore, the anatomy of the compressor plays an important role in choosing the refrigerant.

1. Compressors can be divided into several categories based on their structure as:

a. Positive Displacement: Refrigerant is compressed to high temperature via changing the chamber volume. 
(1) Reciprocating

(a) Welded Hermetic- Capacities are between 1 to 15 tons. These are welded structures and tougher to service because of the structural complexity.

(b) Semi-Hermetic - Capacities can range from 15 tons up to hundreds of tons. These compressors can be retrofitted to accommodate another refrigerant.

(2) Rotary:

(a) Rotary Valve - Less than 5 tons Capacity

(b) Rotary Scroll - Capacities between 5 and 10 tons

(c) Rotary Screw- Capacities between 20 and 750 tons.

2. Dynamic: Refrigerant is compressed to high temperature via a rotating component.

a. Axial- Best Suited for higher capacities

b. Centrifugal - Best suited for above 200 Tons capacity

3. Important accessory components of the cooling system include:
a. Refrigerant filter/drier
b. Thermal expansion valve
c. Oil sight glass
d. Compressor oil.

Of all the above-mentioned parts, compressor oil is the most important factor in choosing an alternate refrigerant. The compressor oil used with R-22 is a mineral oil or alkyl benzene while the replacement refrigerants might require a POE oil that is more viscous than the former. If the compressor has been replaced recently or the system is relatively new, it may be equipped with POE oil, wherein adding an alternate refrigerant to the system might be a viable solution. Whereas most of the older systems use mineral oil, which is less viscous than POE oil. Also, mineral oil does not work well with the latest alternate refrigerants.

\section{B.3 Analysis of recommended alternatives $R-407$ and $R-438$ and ad- ditional system considerations}

This section provides an additional analysis concerning system considerations while retrofitting $\mathrm{R}-22$. This section also reviews the concerns, issues, and challenges of the retrofit procedure. 


\section{B.4 System modifications}

The composition of R-407 and R-438 refrigerants has been designed to provide performance comparable to R-22 in terms of both capacity and energy efficiency. As a result, minimal system modifications are anticipated when retrofitting.

Note: R-407 and R-438 refrigerants should not be mixed with other refrigerants. Mixing these refrigerants with any other CFC or HCFC refrigerants, or mixing two different alternative refrigerants, may have an adverse effect on system performance. "Topping off" a CFC or HCFC refrigerant with any other refrigerant is not recommended.

\section{B.5 Lubricants and system oil management}

Lubricant selection is based on many factors, including compressor wear characteristics, material compatibility, and lubricant/refrigerant solubility (which can affect oil return to the compressor). R-407 and R-438 refrigerants are compatible with traditional and new lubricants.

Field experience has shown that R-407 and R-438 refrigerants will work successfully with the existing mineral oil (or alkylbenzene) in most systems. In some poorly designed, maintained, or operated R-22 systems, or in split systems with complex piping or component arrangements where the evaporator is positioned substantially lower than the condensing unit, the oil may not consistently return to the compressor. If oil return issues exist with R-22 operation, it is recommended that corrective actions be taken before converting to R-407 and R-438 refrigerants.

When oil level sight glasses are present in the compressor, oil levels should be monitored during initial operation with the R-407 and R-438 refrigerants. If the oil level falls below the minimum allowed, top off the oil to the minimum level with the existing oil type. Do not fill to maximum, as the level may rise again. Should the oil level fall continuously, or suffer large oscillations during an operating cycle, addition of POE lubricant has proven effective in restoring adequate oil return rates. An addition of $\mathrm{POE}$ lubricant (approximately 20\% of the total oil charge) should be considered. This can be followed, if necessary, by further small increments of POE, until the oil level returns to normal. 
When adding POE oil to the system, it is important to ensure that the oil level (immediately after addition) is kept below the system mid-point (e.g., mid-sight glass) oil level. In most cases, the process of recovering R-22 at the start of the retrofit also removes some of the existing lubricant from the system. As a result, there should be sufficient space for the addition of POE, if deemed necessary. If there is concern about over-filling the oil sump, some of the existing mineral oil or alkylbenzene can be drained before the equivalent addition of POE.

\section{B.6 Systems with liquid receivers}

When converting a refrigeration or $\mathrm{AC}$ system with a liquid receiver from R-22 to R-407 and R-438 refrigerants, there is a possibility of trapping oil in the receiver by formation of a separate layer if the oil discharge rate of the compressor is high, for example, when there is no oil separator system. Because it is impossible to know at any given time what the oil discharge rate of any compressor is, and because the oil discharge rate may change over time, for systems with liquid receivers and no oil separators, it is recommended that an addition of some POE (approximately $20 \%$ of the total oil charge) be made during the conversion. The addition of the appropriate POE for the system will assist in maintaining adequate oil solubility in the receiver in the event of a high discharge of oil from the compressor. There is no need to perform multiple system flushes or to remove all of the mineral oil or alkylbenzene when converting to R-407 and R-438 refrigerants.

Systems that have oil separators, such as supermarket parallel racks, when converted to R-407 and R-438 refrigerants, have typically maintained lower oil circulation rates and have not required the addition of POE to maintain solubility in liquid receivers.

\section{B.7 Enhanced surface tubing}

In systems containing enhanced tube surfaces in heat exchangers, large amounts of oil in circulation could potentially inhibit heat transfer and negatively impact system performance. If a specific system with enhanced heat transfer tubes is suspected or known to have high oil circulation rates, a partial charge (approximately 20\%) of POE in the existing mineral oil will provide increased solubility of the lubricant in the refrigerant. 


\section{B.8 Refrigerant migration and oil miscibility Direct Expansion Systems with Screw Compressors}

The complex lubrication and oil management system associated with screw compressors requires special consideration and evaluation when retrofitting to any alternate refrigerant. Depending on the system design, oil circulation rates vary and may far exceed typical rates seen with common reciprocating and scroll compressors, even when oil separation systems are installed.

To ensure that the periods of high oil circulation rates do not lead to oil logging and performance concerns, for these systems, the use of original equipment manufacturer (OEM) approved POE lubricant is recommended when retrofitting an R-22 system to an HFC alternative, such as R-407 and $\mathrm{R}-438$ refrigerants. To ensure adequate oil return through these complex screw systems, the change from the existing lubricant to POE should take place while the system is still operating with R-22. Once the system has been converted to POE, the retrofit from R-22 to R-407 and R-438 refrigerants should proceed as outlined in the above noted guidelines.

Consultation with the chiller and screw compressor OEMs on topics beyond oil management is also recommended for these systems. There may be additional system-specific elastomeric seals in the compressor that may must be replaced during the retrofit or programmed control settings related to pressure and temperature readings that would require involvement of the OEM for slight set point changes.

\section{B.9 Liquid refrigerant control}

The potential problems that poor liquid refrigerant control can cause in a refrigeration or air-conditioning system can be severe and difficult to predict with certainty. Where flooding, slugging, or refrigerant migration can occur, corrective action should be taken. The proper course of action is normally dependent on the compressor type, system design, type of problem, and the refrigerant/ lubricant combination. Compressor or equipment manufacturers should be consulted for detailed guidance on liquid control for a specific system. 
While undesirable for reasons previously described and often dependent on system design, management of liquid refrigerant in general may be accomplished by using a variety of equipment or control strategies:

- Minimize Refrigerant Charge. Charge system with minimum amount of refrigerant required for proper operation. Keep the tubes in condensers, evaporators, and connecting lines to smallest practical size.

- Pump Down Cycle (Continuous or One-Time). Isolates the refrigerant when compressor is not in operation, preventing refrigerant migration.

- Crank Case Heaters. Maintains oil in the compressor at a temperature higher than coldest part of the system, driving refrigerant out of the compressor.

- Suction Line Accumulators. Provides a temporary storage vessel to trap liquid refrigerant that has flooded back, which is especially important for heat pump systems.

- Flood Back, Superheat, and Temperature Glide. Flood back (incomplete evaporation of liquid refrigerant in the evaporator), due to inadequate superheat, may be caused by an oversized or improperly adjusted thermal expansion valve (TXV) and can lead to liquid slugging and/or bearing washout in the compressor. For air-conditioning or refrigeration systems being converted from R-22 to R-407 and R-438 refrigerants, the mass flow rates are fairly similar, such that a TXV (valve body, power-head, or nozzle/orifice) properly sized and operating well for R22 should not need replacement when switching to R-407 and R-438 refrigerants.

However, it may be necessary to slightly adjust the TXV due to the temperature glide effect and small suction pressure differences of the new refrigerant. The need for adjustment will depend on current valve set points and amount of superheat desired to achieve appropriate system performance. Because the mass flow rates and pressure-temperature curves for R-22 and R-407 and R-438 refrigerants are very close, only minor adjustments should be required for properly sized components. Conversion kits are available to convert some older non-adjustable TXVs into adjustable type, without replacing the valve, if need be.

R-407 and R-438 refrigerants will also work well in systems designed with fixed expansion devices, such as capillary tubes, pistons, or other fixed orifices; in most cases, a change in expansion device is not required. In these non-adjustable systems, the refrigerant charge size is critical, and extra 
care should be used when weighing and charging the refrigerant. As stated in the retrofit steps, when charging R-407 and R-438 refrigerants to these critically charged systems, begin with approximately $85 \%$ of the original $\mathrm{R}-22$ charge weight. Once conditions stabilize, additional refrigerant can be added in small increments as needed to achieve the desired superheat for the system.

During any refrigerant charging process, as system pressures are being monitored, if the condenser (head) pressure rises significantly above typical levels expected with R-22 and necessary refrigerant charge weight has not been reached, STOP CHARGING and ensure there is no restriction in the flow. Fixed expansion devices are designed with small diameters to properly meter flow; a restriction in the path can lead to high condenser pressures and/or starving of the evaporator.

If condenser pressures remain high after verifying the system has no line restriction and is not overcharged, the suction superheat should be checked. If the suction superheat is higher than typically observed with R-22, it is possible that the existing fixed expansion device is undersized. The replacement option for each type of device and system will vary based on design. However, in general, fixed pistons and orifices can be replaced with an orifice of a larger size or with a TXV designed for use with R-22. Capillary tubes, if undersized for R-407 and R-438 refrigerants, can also be replaced with a shorter or wider tube or with a TXV designed for use with R-22.

\section{B.10 Filter drier}

Change the filter drier during the retrofit. This is a routine system maintenance practice after the system has been open to air. There are two types of filter driers commonly used, solid core and loose filled. Replace the drier with the same type currently in use in the system. The drier label will list the refrigerants that can be used with that drier. Select a drier specified to work with R-407 and R-438 refrigerants. (Many driers sold today are "universal" i.e., they will work with most fluorocarbon refrigerants.) Check with your refrigeration distributor for the correct drier to use in your system.

\section{B.11 Elastomeric seals}

R-22 and, to a lesser extent, R-22-containing refrigerant blends, interact relatively strongly with many elastomers, causing significant swelling and, often, over time, a measurable increase in hardness. R-407 and R-438 
refrigerants, like other HFC refrigerants, do not have as strong of an effect on elastomers commonly used as seals in refrigeration systems. As a result, when performing an R-22 retrofit to an HFC alternative, it is possible for leaks to occur at elastomeric seals that have been previously exposed to $\mathrm{R}-22$ refrigerant. This is not a problem attributable specifically to the use of R-407 and R-438 refrigerants. However, such seal leaks have been reported when replacing R-22 with HFC refrigerants. Components commonly affected are Schrader core seals, liquid level receiver gaskets, solenoid valves, ball valves, flange seals, and some shaft seals on open drive compressors. Leaks do not occur in every system retrofitted, and, in practice, it is difficult to predict whether such leaks will occur. (As a rule of thumb: the older the system, the higher the probability that leaks will be observed after a retrofit.)

Consequently, it is recommended to change elastomeric seals and gaskets as a matter of course during a retrofit, particularly any system-critical seals (those that would require removal of the refrigerant charge to allow seal replacement, e.g., liquid receiver, refrigerant high-pressure side, etc.). It is also recommended to have spare seals for other components available during restart of the system. The same type of seal can be used, it should just be a new one that has not previously been in R-22 service. A rigorous leak check regime pre- and post-retrofit will minimize any refrigerant losses. Obviously, any seals found to be leaking before the retrofit takes place should be replaced during the retrofit. 


\section{Appendix C: Discussion of R-22 Elimination Methods and Procedures}

\section{C.1 R-22 elimination methods from existing equipment}

In this section discusses two methods to eliminate R-22 from existing equipment before end of life. One method is to retrofit the equipment to accommodate an alternate refrigerant and the other is to replace the complete condensing unit. Though several R-22 replacement refrigerant products in the market advertise as "drop-ins," we do not recommend using this option. There is no absolute alternate to R-22 that can be used without system modification. R-22 systems were originally designed to operate with an HCFC compound and must be retrofitted to use an alternate HFC refrigerant. The compressor replacement method has not been discussed in greater detail as this procedure is unique to the compressor type (such as scroll, screw, reciprocating etc.). It is recommended to contact compressor manufacturers to get accurate information for the compressor replacement procedures.

\section{C.2 Retrofit existing equipment to alternative refrigerant}

To retrofit the refrigerant, the compressor must be modified to accommodate physical properties of the alternate refrigerant. Modification of the equipment also depends on the compressor type, and some models such as welded hermetic compressors can be difficult to retrofit because of their structure. Therefore, it is advised to perform further individualized analysis while performing retrofit for each system. The following section outlines a generalized procedure for a basic HVAC retrofit to accommodate R-22.

1. Establish baseline performance with existing refrigerant. (It may be necessary to perform a heat load analysis.)

2. Remove existing R-22 refrigerant from the system into a recovery cylinder. Weigh the amount removed.

3. Replace the filter drier (TXV, if necessary) and critical elastomeric seals/ gaskets. Critical seals are ones that are difficult to isolate and/or service while operating or require removal of the entire refrigerant charge, i.e., liquid receiver level gauge, before replacement of new refrigerant.

4. Evacuate system and check for leaks.

5. Charge with replacement refrigerant such as R-407 or R-438.

6. Remove as a liquid only from charging cylinder. 
7. The initial charge amount should be approximately $85 \%$ of the standard charge for R-22. The final charge amount will vary by the system but will be approximately the same weight as with R-22.

8. Start-up the system, monitor, and adjust TXV and/or charge size to achieve optimum superheat.

9. Monitor oil levels in compressor. Add oil as required to maintain proper levels.

10. Label system for the refrigerant and lubricant used.

\section{C.3 System considerations while retrofitting the equipment}

1. When adding POE oil to the system, it is important to ensure that the oil level (immediately after addition) is kept below the system mid-point (e.g., mid-sight glass) oil level. In most cases, the process of recovering R-22 at the start of the retrofit also removes some of the existing lubricant from the system. As a result, there should be sufficient space for the addition of POE, if deemed necessary.

2. The complex lubrication and oil management system associated with screw compressors requires special consideration and evaluation when retrofitting to any alternate refrigerant. Depending on the system design, oil circulation rates vary and may far exceed typical rates seen with common reciprocating and scroll compressors, even when oil separation systems are installed.

3. It is recommended to change elastomeric seals and gaskets as a matter of course during a retrofit, particularly any system-critical seals (those that would require removal of the refrigerant charge to allow seal replacement, e.g., liquid receiver, refrigerant high-pressure side, etc.).

\section{Replace the Entire Condensing Unit}

Replacing the entire condensing unit requires the following steps:

1. Disconnect the power supply line by cutting power at the breaker. Then disconnect the electrical line from the unit.

2. Clamp and disconnect the refrigerant lines. Check for any refrigerant leaks from the units and drain all the refrigerant from the piping.

3. Remove the entire condensing unit from its spot, which is usually a concrete pad.

4. Place the new unit on the location. Leave enough space around the new unit to make sure electrical and refrigerant lines reach. 
5. Reconnect the refrigerant lines and recharge with new refrigerant. Test for refrigerant leaks and seal any loose connections.

6. Reconnect the electrical lines to restore power to the unit.

7. Turn on the system and test if the cycles are operating correctly.

\section{C.4 Considerations while replacing the condensing unit}

1. Replacing a condensing unit means the old air handling system and other piping will have to work with a new condensing unit. This can result in compatibility issues between both systems. '

2. R-22 refrigerants must be recovered completely before adding a new refrigerant as it can result in compatibility issues in operation. Also, repairing a system always increases the probability of exposing an environmentally unfavorable gas into the atmosphere.

\section{C.5 What are installations doing now}

To better determine that current R-22 elimination strategy at IMCOM installations, we interacted with officials from Fort Hood and Fort Carson. Fort Hood has been actively involved in elimination of R-22 systems from its equipment inventory, by replacing complete condensing units on the basis of need. The main driver for this condenser replacement has been a response to the need to perform a major repair on an aging R-22 system and their intent to proactively eliminate R-22. As of now, they have eliminated R-22 from approximately 100 systems in this manner. They have been using alternate refrigerants R-422B and R-417A for their systems. At the time of our discussions, they had not encountered any major complications in the process.

We learned that Fort Hood had been using GSA vendors to purchase R-22 whereas Fort Carson had been purchasing R-22 through a local vendor. Therefore, both installations were dependent on the commercial R-22 market rather than Army reserves, which is primarily reserved for tactical purposes. Both installations reported they had had no issues procuring R22 for their equipment but Fort Carson had a concern regarding the future of R-22 availability from their local vendor. Additionally, both installations were recapturing R-22 from old equipment. Tables $\mathrm{C}-1$ to $\mathrm{C}-4$ summarize costs associated with refrigerant replacement. 
Table C-1. Cost to retrofit existing equipment with alternative refrigerant.

\begin{tabular}{|l|l|}
\hline Equipment Capacity & Cost Range \\
\hline 0 to 5 Ton & $\$ 2000-\$ 4500$ \\
\hline 25 Ton & $\$ 5000-\$ 7500$ \\
\hline 50 Ton & $\$ 9000-\$ 13,500$ \\
\hline 75 Ton & $\$ 13,000-\$ 18,000$ \\
\hline 100 Ton & $\$ 18,000-27,000$ \\
\hline 125 Ton & $\$ 22,000-\$ 31,500$ \\
\hline 150 Ton & $\$ 27,000-\$ 40,500$ \\
\hline Data acquired from commercial contractors and manufacturers for budgetary calculations \\
\hline
\end{tabular}

Table C-2. Cost to replace the compressor.

\begin{tabular}{|c|c|c|c|c|c|c|c|c|}
\hline \multicolumn{9}{|c|}{ Compressor Type } \\
\hline \multicolumn{3}{|c|}{ Scroll } & \multicolumn{3}{|c|}{ Rotary } & \multicolumn{3}{|c|}{ Reciprocating } \\
\hline Ton & $\begin{array}{l}\text { Cost per } \\
\text { unit (\$) }\end{array}$ & $\begin{array}{l}\text { Cost per ton } \\
(\$)\end{array}$ & Ton & $\begin{array}{l}\text { Cost per } \\
\text { unit (\$) }\end{array}$ & $\begin{array}{l}\text { Cost per } \\
\text { ton }(\$)\end{array}$ & Ton & $\begin{array}{l}\text { Cost per } \\
\text { unit (\$) }\end{array}$ & $\begin{array}{l}\text { Cost per } \\
\text { ton }(\$)\end{array}$ \\
\hline 1.9 & 550 & 275 & 1.25 & 455 & 364 & 10 & 10900 & 1090 \\
\hline 2.35 & 610 & 260 & 1.45 & 460 & 317 & 20 & 17200 & 860 \\
\hline 2.82 & 660 & 220 & 1.68 & 495 & 295 & 30 & 19400 & 647 \\
\hline 3.3 & 685 & 208 & 2 & 520 & 260 & 40 & 22400 & 560 \\
\hline 3.83 & 745 & 195 & 2.37 & 565 & 238 & 50 & 28200 & 564 \\
\hline 4.1 & 810 & 203 & 2.67 & 595 & 223 & 75 & 30400 & 405 \\
\hline 4.8 & 855 & 178 & 3.53 & 635 & 180 & 130 & 36000 & 277 \\
\hline \multirow[t]{8}{*}{5} & 870 & 174 & 4.43 & 745 & 168 & & & \\
\hline & & & 5.08 & 805 & 158 & & & \\
\hline & & & 5.22 & 1025 & 196 & & & \\
\hline & & & 7.31 & 1500 & 205 & & & \\
\hline & & & 9.95 & 1775 & 178 & & & \\
\hline & & & 11.6 & 2175 & 188 & & & \\
\hline & & & 15.25 & 2825 & 185 & & & \\
\hline & & & 17.7 & 3050 & 172 & & & \\
\hline
\end{tabular}

Table C-3. Average compressor replacement costs.

\begin{tabular}{|l|l|}
\hline Equipment Capacity & Cost per ton $(\$)$ \\
\hline 1 to 5 tons & Average $\$ 1200$ \\
\hline 5 to 25 Tons & Average $\$ 850-\$ 550$ \\
\hline & \\
\hline Ranges & Assumptions based on the above data \\
\hline 1 to 5 & $\$ 200-\$ 400$ \\
\hline 5 to 25 & $\$ 400-\$ 1100$ \\
\hline 25 to 50 & $\$ 600-\$ 900$ \\
\hline
\end{tabular}




\begin{tabular}{|l|l|}
\hline Equipment Capacity & Cost per ton $(\$)$ \\
\hline 50 to 100 & $\$ 300-\$ 600$ \\
\hline Above 100 & $\$ 300-\$ 400$ \\
\hline Cost of compressor replacement from mechanical contractor estimates \\
\hline
\end{tabular}

Table C-4. Cost to replace condensing unit at EOL:

\begin{tabular}{|l|l|l|l|l|l|}
\hline Equipment Type & $\mathbf{0}$ to 5 Tons & $\mathbf{6}$ to 25 Tons & $\mathbf{2 6}$ to 50 Tons & 51 to 100 Tons & Above 101 Tons \\
\hline $\begin{array}{l}\text { Chilled Water } \\
\text { Systems }\end{array}$ & $\$ 16,697$ & $\$ 101,370$ & $\$ 107,758$ & $\$ 123,340$ & $\$ 255,048$ \\
\hline $\begin{array}{l}\text { Direct Expansion } \\
\text { Systems }\end{array}$ & $\$ 4,081$ & $\$ 8,469$ & $\$ 23,679$ & $\$ 29,475$ & $\$ 102,993$ \\
\hline Package Units & $\$ 12,740$ & $\$ 55,295$ & 112,843 & $\$ 212,436$ & $\begin{array}{l}\text { No Package Units } \\
\text { were found to be } \\
\text { above } 100 \text { tons }\end{array}$ \\
\hline
\end{tabular}




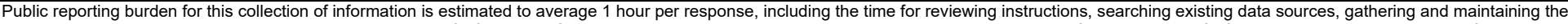

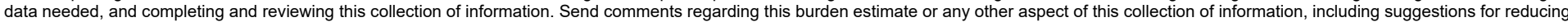

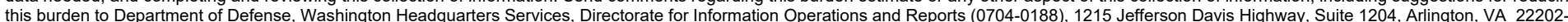

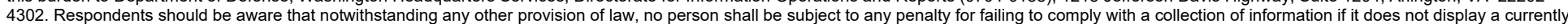
valid OMB control number. PLEASE DO NOT RETURN YOUR FORM TO THE ABOVE ADDRESS
1. REPORT DATE (DD-MM-YYYY)
March 2021
2. REPORT TYPE Final Report

2. REPORT TYPE
Final Report

\section{TITLE AND SUBTITLE}

Army R-22 Refrigerant Phase-Out Strategy

James P. Miller, Anthony R. Latino, Chandana Konidala, Raymond Patenaude, and Gonzalo Perez

\begin{tabular}{|l|}
\hline $\begin{array}{l}\text { 3. DATES COVERED (From - To) } \\
\text { FY19-FY21 }\end{array}$ \\
$\begin{array}{l}\text { 5a. CONTRACT NUMBER } \\
\text { W9132T-20-P-O024 }\end{array}$ \\
\hline $\begin{array}{l}\text { 5b. GRANT NUMBER } \\
\text { 5c. PROGRAM ELEMENT } \\
\text { U452464 }\end{array}$ \\
$\begin{array}{l}\text { 5d. PROJECT NUMBER } \\
\text { 474139 }\end{array}$ \\
\hline $\begin{array}{l}\text { 5e. TASK NUMBER } \\
\text { 5f. WORK UNIT NUMBER } \\
\text { 8. PERFORMING ORGANIZATION REPORT } \\
\text { NUMBER } \\
\text { ERDC/CERL TR-21-9 } \\
\text { IMCOM HQ } \\
\text { 11. SPONSOR/MONITOR'S REPORT } \\
\text { NUMBR(S) }\end{array}$ \\
\hline
\end{tabular}

\section{DISTRIBUTION / AVAILABILITY STATEMENT}

Approved for public release; distribution is unlimited.

\section{SUPPLEMENTARY NOTES}

MIPR 11268077

\section{ABSTRACT}

R-22 (also known as HCFC-22) is one of the most widely used refrigerants in U.S. Army air-conditioning and refrigeration (AC\&R) systems since the phase-out of R-12 refrigerant in 1995. The need to phase out R-22 is at-tributed to its global warming potential and high ozone-depleting capability. The U.S. Army has tens of thousands of aging AC\&R systems that will remain dependent on R-22, or one of the recently developed substitutes for R-22, until they reach the end of their operational life.

This project conducted a survey to understand the current R-22 usage and types of R-22 AC\&R equipment that are in use across Installation Management Command (IMCOM) installations. This study describes several methods to remove or retrofit R-22 from typical AC\&R equipment and implementation strategies to meet the stated goal of eliminating R-22 from IMCOM installations. The scope of this project included the review of BUILDER SMS data for IMCOM installations, which included data on 13,000 pieces of comfort cooling equipment for 31 installations. The report also provides an analysis of several R-22 alternatives and their physical properties and compatibility. Mission critical tactical cooling that uses R-22 refrigerant was not within the scope of this project.

\section{SUBJECT TERMS}

Refrigerants-Environmental aspects Air conditioning

\section{SECURITY CLASSIFICATION OF:}

\section{a. REPORT \\ Unclassified}

\section{b. ABSTRACT}

Unclassified
Air conditioning-Equipment and supplies Ozone layer depletion

\section{c. THIS PAGE}

Unclassified

$\begin{gathered}\text { 17. LIMITATION } \\ \text { OF ABSTRACT } \\ \text { SAR }\end{gathered}$

Military bases

\begin{tabular}{c|c} 
18. NUMBER \\
OF PAGES
\end{tabular}

19a. NAME OF RESPONSIBLE PERSON

19b. TELEPHONE NUMBER (include area code) 